\title{
Redox switching and oxygen evolution electrocatalysis in polymeric iron oxyhydroxide films
}

\author{
Michael E. G. Lyons* and Michael P. Brandon \\ Received 2nd September 2008, Accepted 18th December 2008 \\ First published as an Advance Article on the web 6th February 2009 \\ DOI: $10.1039 / \mathrm{b815338h}$
}

Outstanding issues regarding the redox switching characteristics and the oxygen evolution reaction (OER) electrocatalytic behaviour of multicycled iron oxyhydroxide films in aqueous alkaline solution have been examined. Charge percolation through the hydrous layer has been quantified, using cyclic voltammetry, in terms of a charge transport diffusion coefficient $D_{\mathrm{CT}}$ which admits a value of $c a .3 \times 10^{-10} \mathrm{~cm}^{2} \mathrm{~s}^{-1}$. Steady-state Tafel plot analysis and electrochemical impedance spectroscopy have been used to elucidate the kinetics and mechanism of oxygen evolution. Tafel slope values of $c a .60 \mathrm{mV} \mathrm{dec}{ }^{-1}$ and $c a .120 \mathrm{mV} \mathrm{dec}^{-1}$ are found at low and high overpotentials respectively, whereas the reaction order with respect to hydroxide ion activity changes from $c a .3 / 2$ to $c a$. 1 as the potential is increased. These observations are rationalised in terms of a kinetic scheme involving Temkin adsorption and the rate determining formation of a physisorbed hydrogen peroxide intermediate on the oxide surface. The dual Tafel slope behaviour is ascribed to the potential dependence of the surface coverage of adsorbed intermediates.

\section{Introduction}

In contrast to electrode modification by electroactive polymer materials, comparatively little attention has been paid to redox active hydrated polymeric metal oxides, which may be generated on the surface of the parent metal via continious potential cycling in aqueous solution. A survey of the electrochemistry of these materials was provided by Burke and Lyons. ${ }^{1}$ In the latter work a distinction was made between compact anhydrous oxides such as spinel or perovskite materials, in which the oxygen is present only as a bridging species between two metal cations, and microdispersed hydrous oxides where oxygen is present not just as a bridging species, but also as $\mathrm{O}^{-}$, $\mathrm{OH}$ and $\mathrm{OH}_{2}$ species in co-ordinated terminal group form. In many cases, the latter materials when in contact with aqueous media contain considerable quantities of loosely bound and trapped water, plus occasionally electrolyte species. Whilst compact oxides are usually prepared via thermal decomposition of an inorganic precursor salt, the dispersed oxides are almost invariably prepared in an aqueous environment via in situ electrochemical methods. In this methodology the potential of an electrode of the parent metal is cycled repetitively between suitable limits in a solution of appropriate $\mathrm{pH}$. Very often the material prepared in this manner is deposited in the kinetically most-accessible, rather than the thermodynamically most-stable, form. Therefore these materials are often significantly amorphous and are prone to rearrangement

Physical and Materials Electrochemistry Laboratory, School of Chemistry, University of Dublin, Trinity College, Dublin 2, Ireland. E-mail:melyons@tcd.ie; Fax: +353(0)16712826;

Tel: $+353(0) 18962051$ in a manner that is strongly influenced by factors such as temperature and $\mathrm{pH}$.

A duplex layer model for the oxide/solution interface was proposed some time ago by Burke and co-workers. ${ }^{2,3}$ In this approach, one has an inner compact anhydrous layer $\mathrm{MO}_{x}$ and an outer microdispersed hydrous layer of general form $\mathrm{MO}_{a}(\mathrm{OH})_{b}\left(\mathrm{OH}_{2}\right)_{c}$. Little potential is envisaged to be dropped across the inner layer, whereas the majority of the potential drop occurs at the compact layer/dispersed layer interface. Furthermore, dispersed hydrated oxide materials exhibit good electrocatalytic potentiality due to their skeletal nature. The latter structural feature permits a major increase in the number of oxyions participating in the electrode reaction. The electrons are readily shuttled along the polymer-like structural chain to the support metal electrode, via a process of self exchange between neighbouring oxy metal groups.

A final, but important, feature of hydrous oxides is their acid/base chemistry - many oxides are amphotheric, i.e. they tend to function as bases (adsorbing protons or losing $\mathrm{OH}^{-}$ ions and thereby acquiring positive charge) at low $\mathrm{pH}$, and act as acids (adsorbing $\mathrm{OH}^{-}$ions or losing protons and thereby becoming negatively charged) at high $\mathrm{pH}$. Important aspects of this behaviour were addressed by Burke and co-workers. ${ }^{4-10}$ Dispersed hydrated oxides exhibit a super-Nernstian shift in redox potential with changes in solution $\mathrm{pH} .{ }^{10}$ This may be attributed to the formation of anionic species at the interface due to hydrolysis reactions. The process involved is regarded as proton loss from coordinated water molecules or excess $\mathrm{OH}^{-}$ion coordination by the central metal ion in the hydrous oxide material. The charge on the metal ion is important. If the latter is of a high positive value then the oxide will be anionic. Counterion species such as $\mathrm{H}^{+}$or $\mathrm{M}^{+}$will reside in the solution phase permeating the polymeric oxide matrix. 
In the present communication, we report on the redox properties, and oxygen evolution electrocatalytic behaviour, of hydrous iron oxyhydroxide films in alkaline solution. This is a development of a body of work published some years ago by one of the present authors, ${ }^{11,12}$ and clarifies some issues left unresolved in that original study. Recently there has been a revival in interest in the optimisation of OER anode materials, since the oxygen evolution overpotential is the principle factor in limiting the efficiency of hydrogen production via alkaline water electrolysis. ${ }^{13}$

\section{Experimental}

The experiments were conducted with working electrodes constructed either from polycrystalline iron wire ( $2 \mathrm{~mm}$ diameter, $\sim 0.0314 \mathrm{~cm}^{2}$ exposed geometric area, purity $99.9+\%$, supplied by Aldrich) sealed directly into glass, or from polycrystalline iron foil $\left(1 \mathrm{~cm}^{2}\right.$ exposed area, purity $99.995 \%$ (metals basis), as supplied by Alfa Aesar (Johnson Matthey)). Before the commencement of all experiments, the working electrode surfaces were polished to a "mirror bright" finish using a slurry of 0.05 micron alumina powder. Sodium hydroxide (pellets supplied by $\mathrm{BDH}$ AnalaR ${ }^{\circledR}$, minimum $98 \%$ purity) solutions served both as the electropolymerization medium, and as a supporting electrolyte for the redox switching and electrocatalytic studies. These solutions were prepared using millipore water (resistivity $18 \mathrm{M} \Omega \mathrm{cm}$ ). No excess salts were added and all experiments were conducted at $25 \pm 1{ }^{\circ} \mathrm{C}$. A standard three electrode cell arrangement was used, with a platinum foil employed as the counter electrode.

A mercuric-mercuric oxide reference electrode, $\mathrm{Hg} / \mathrm{HgO}$, $1 \mathrm{M} \mathrm{NaOH}$, (Radiometer Analytical, cat no. XR400) was utilised as the reference standard. When used in $\mathrm{NaOH}$ solutions of different concentrations, the potential of the $\mathrm{Hg} / \mathrm{HgO}$ electrode was checked relative to a second $\mathrm{Hg} / \mathrm{HgO}$, $1 \mathrm{M} \mathrm{NaOH}$ electrode, both before and after the experiment. No significant potential drift was noted after such experiments, implying that the concentration of the $\mathrm{NaOH}$ in the reference electrode chamber remains effectively constant over the time scale of typical polarisation measurements ( $c a .2-3 \mathrm{~h})$. In any case, the $1 \mathrm{M} \mathrm{NaOH}$ solution in the reference electrode, was changed regularly to ensure experimental consistency.

The electrochemical measurements were performed using either, an analogue EG\&G PAR Model 273 potentiostat in combination with a Linseis $17100 \mathrm{X}-\mathrm{Y}$ recorder, or a computer controlled, digital, Zahner Elektrik IM6 electrochemical measurement unit. The latter is equipped with an in-built frequency response analyser (FRA), which was used to examine the complex impedance response, under active oxygen evolution conditions, in the case of one of the studied oxide films. Complex non-linear least squares (CNLS) fitting of raw impedance data to equivalent circuit models was conducted using the SIM module of the IM6 Thales software suite. The impedance technique was also used, in all cases, to determine the uncompensated electrolyte resistance between the oxide coated working electrode and the reference electrode. This parameter was specifically considered in the Tafel plot measurements, where the data is presented in $i R$ compensated form.

Charge storage capacity (redox capacity), $Q$, were determined via integration of the peaks recorded in the voltammetric profiles at slow sweep rates. The redox capacity is directly proportional to the layer thickness.

\section{Results and discussion}

\section{Cyclic voltammetry measurements}

A series of voltammetric curves, are presented in Fig. 1, recorded $\left(-1.42 \mathrm{~V}\right.$ to $\left.0.68 \mathrm{~V}, 40 \mathrm{mV} \mathrm{s}^{-1}\right)$ during the initial stages of the electrodeposition of a multilayer microdisperse hydrous iron oxyhydroxide film in $1 \mathrm{M} \mathrm{NaOH}$ solution. In Fig. 2 the profiles arising from the application of an extended number of potential cycles are presented. The experimental conditions used during the multicycling procedure has previously been optimised. ${ }^{12}$ The voltammetric profiles exhibit quite an amount of fine structure, especially during the earlier sweeps (resolved most clearly in Fig. 1). For a polycrystalline Fe electrode polished to a "mirror bright" finish, we usually observed four well-defined anodic peaks (A1-A4) and two cathodic peaks $(\mathrm{C} 1, \mathrm{C} 2)$ during the initial stages of oxidation, reflecting surface redox processes involving bound oxy iron species. This fine structure has been observed by other workers, ${ }^{14-24}$ and the general features of the voltammetric response remain unchanged, even if the concentration of base is increased. The various features have been previously assigned, both by us, ${ }^{12}$ and other workers. ${ }^{14-24}$ Our viewpoint on the voltammetric peak assignment is summarised presently.

Peak A1 is most probably due to the formation of a layer of adsorbed hydroxy species,

$$
\mathrm{Fe}+\mathrm{OH}^{-} \rightarrow \mathrm{FeOH}(\text { ads. })+2 \mathrm{e}^{-},
$$

combined with the electrochemical displacement of adsorbed hydrogen:

$$
\mathrm{FeH}(\text { ads. }) \rightarrow \mathrm{Fe}+\mathrm{H}^{+}+\mathrm{e}^{-}
$$

Peak A2 may then represent the conversion of both $\mathrm{Fe}$ and $\mathrm{FeOH}($ ads.) to a thin film of $\mathrm{Fe}(\mathrm{II})$ hydroxide or oxide according to:

$$
\begin{aligned}
& \mathrm{FeOH}(\text { ads. })+\mathrm{OH}^{-} \rightarrow \mathrm{Fe}(\mathrm{OH})_{2}+\mathrm{e}^{-} \\
& \mathrm{FeOH}(\text { ads. })+\mathrm{OH}^{-} \rightarrow \mathrm{FeO}+\mathrm{H}_{2} \mathrm{O}+\mathrm{e}^{-}
\end{aligned}
$$

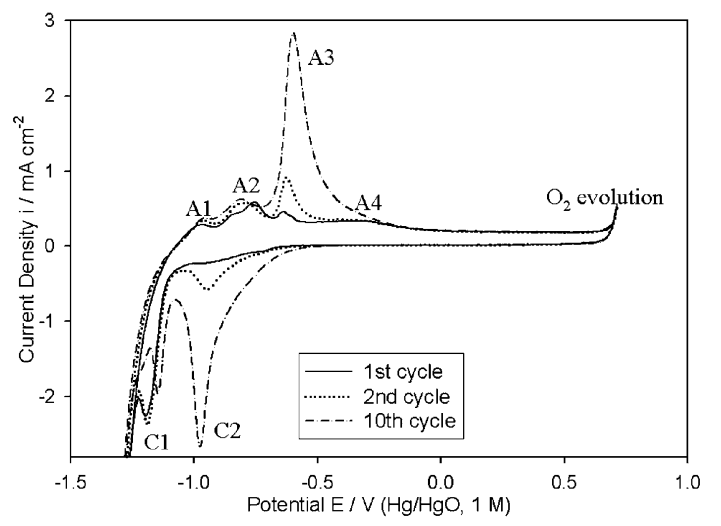

Fig. 1 1st, 2nd and 10th voltammetric cycles $(-1.42 \mathrm{~V}$ to $0.68 \mathrm{~V}$, $40 \mathrm{mV} \mathrm{s}^{-1}$ ) of a freshly prepared bright polycrystalline iron electrode in $1 \mathrm{M} \mathrm{NaOH}$ at $25^{\circ} \mathrm{C}$. 


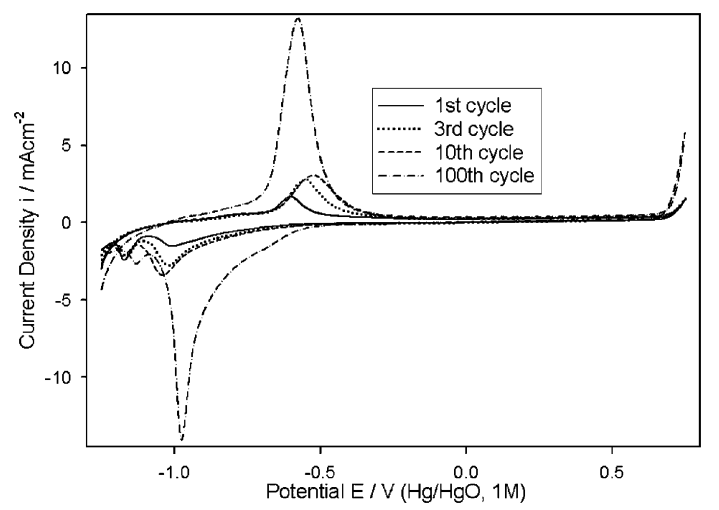

Fig. 2 Analytical CVs (cycle number as indicated in the legend) recorded at $40 \mathrm{mV} \mathrm{s}^{-1}$, of an initially bright polycrystalline $\mathrm{Fe}$ electrode in $1 \mathrm{M} \mathrm{NaOH}$. All CVs recorded between -1.3 and $0.75 \mathrm{~V}$ at $25{ }^{\circ} \mathrm{C}$. The intervening cycles were performed between the same limits at $300 \mathrm{mV} \mathrm{s}^{-1}$.

In simple terms peak A3 is attributed to the following $\mathrm{Fe}(\mathrm{II}) / \mathrm{Fe}(\mathrm{III})$ redox transformation:

$$
\mathrm{Fe}(\mathrm{OH})_{2}+\mathrm{OH}^{-} \rightarrow \mathrm{FeOOH}+\mathrm{H}_{2} \mathrm{O}+\mathrm{e}^{-}
$$

One should note that with a transition metal such as iron, the aforementioned surface processes are likely to be accompanied by film thickening (i.e. place exchange reactions ${ }^{21,25}$ ), even at quite low potentials.

Peak A3 along with its cathodic counterpart, peak C2 are the only peaks which become enhanced on potential cycling (Fig. 1 and 2). We have previously shown ${ }^{12}$ that the $\mathrm{A} 3 / \mathrm{C} 2$ peaks exhibit the usual characteristic of a hydrous or hyperextended oxide, i.e. a super-Nernstian potential-pH shift, which has the value of $\mathrm{d} E / \mathrm{dpH}=-2.303(3 R T / 2 F)=$ $-0.088 \mathrm{~V} / \mathrm{pH}$ unit at $T=298 \mathrm{~K}$. Hence the latter peak combination is attributed to an $\mathrm{Fe}(\mathrm{II}) / \mathrm{Fe}$ (III) redox transition in a polymeric microdispersed hydrous oxide layer, formed initially (even during the first anodic voltammetric sweep) by hydration of the outer regions of the $\mathrm{Fe}(\mathrm{OH})_{2}$ or $\mathrm{FeO}$ film. By analogy with a scheme produced by Burke and Whelan ${ }^{10}$ for redox switching of iridium oxide films, one may propose that the main redox switching reaction may be written as:

$$
\begin{aligned}
& {\left[\mathrm{Fe}_{2}(\mathrm{OH})_{6}\left(\mathrm{OH}_{2}\right)_{3}\right]^{2-}+3 \mathrm{OH}^{-}} \\
& \quad \rightarrow\left[\mathrm{Fe}_{2} \mathrm{O}_{3}(\mathrm{OH})_{3}\left(\mathrm{OH}_{2}\right)_{3}\right]^{3-}+3 \mathrm{H}_{2} \mathrm{O}+2 \mathrm{e}^{-}
\end{aligned}
$$

The envisaged structure of the oxidised form is depicted schematically in Fig. 3, where the basic dimeric unit of the polymer chain network is presented. The ratio of hydroxide ions to electrons will, by a simple Nernstian analysis, yield the experimentally observed $\mathrm{pH}$ dependence. Peak A4 is also related to an $\mathrm{Fe}(\mathrm{II}) / \mathrm{Fe}(\mathrm{III})$ redox transition-however at this potential it is the inner more amorphous region of the Fe(II) species that is oxidised in the region of the film close to the metal surface. Possibly oxidation products are largely anhydrous phases of $\mathrm{Fe}_{2} \mathrm{O}_{3}, \mathrm{Fe}_{3} \mathrm{O}_{4}$ or $\mathrm{FeOOH}$.

The cathodic peak $\mathrm{C} 1$ corresponds to the reduction of the compact, anhydrous inner layer (see schematic of Fig. 3) according to the following reaction:

$\mathrm{FeO} \cdot \mathrm{FeOOH}+\mathrm{H}_{2} \mathrm{O}+3 \mathrm{e}^{-} \rightarrow \mathrm{Fe}+\mathrm{FeO}_{2}{ }^{2-}+\mathrm{H}_{2} \mathrm{O}+\mathrm{OH}^{-}$

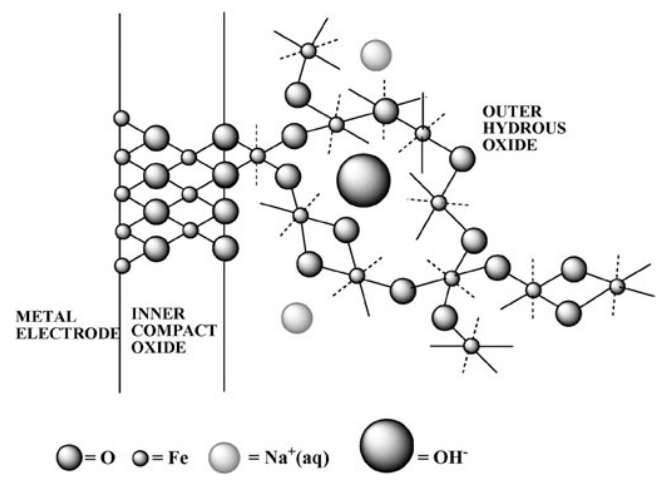

Fig. 3 Schematic representation of the $\mathrm{M} / \mathrm{MO}_{x} / \mathrm{MO}_{a}(\mathrm{OH})_{b}\left(\mathrm{OH}_{2}\right)_{c} /$ electrolyte interface region. $\mathrm{M}=$ metal ion, in this case $\mathrm{Fe}$.

A useful aspect of this reaction is that the charge capacity of peak $\mathrm{C} 1$ (which can be calculated by integration of the peak between appropriate limits) can be used to estimate the extent of the compact layer growth.

A few further points are in order regarding the voltammetric data of Fig. 1. As previously commented, we generally observed four anodic and two cathodic peaks during the initial oxidation of a freshly polished bright Fe electrode. However up to six anodic and five cathodic peaks have been observed ${ }^{23}$ for the same system. While much of this disparity probably arises owing to differing experimental conditions (i.e. upper and lower voltammetric limits, scan rates, pre-treatments) utilised by different workers, the data of Fig. 1 exposes another, more fundamental factor, that will lead to irreproducibility in such voltammetric measurements.

The scan denoted as the "first cycle" was recorded for a freshly prepared iron foil electrode, which had been exposed to alkaline solution for the first time, immediately prior to the experiment. This profile represents what is probably the closest possible approximation (under normal ambient laboratory conditions) to the $\mathrm{CV}$ of an initially "truly bright" $\mathrm{Fe}$ electrode in alkaline solution. In this context "truly bright" refers to an electrode free from any residual anodic oxide that is resistant to removal by normal polishing procedures. The effects of such residual oxide on the ageing of $\mathrm{Ni}$ and $\mathrm{Co}$ electrodes have been discussed by us elsewhere. ${ }^{26,27}$

The above claim regarding the initially "truly bright" electrode is based upon the fact that peak C2 is virtually absent in the first cycle of Fig. 1. In addition the corresponding anodic peak, A3, has a very small charge associated with it on the first cycle. As previously outlined, this peak pair corresponds to the formation and reduction of a hydrous, outer, $\mathrm{Fe}(\mathrm{III})$-oxyhydroxide based, oxide film. In view of this, the first cycle of Fig. 1, obviously represents the very earliest stage of the passivation of a bright Fe electrode, where the formation of the aforementioned hydrous outer oxide is barely significant. The importance of the latter process has obviously increased by the second cycle, which is very similar in profile to that previously presented by us, ${ }^{12}$ for a bright Fe electrode in $1.0 \mathrm{M} \mathrm{NaOH}$ at $40 \mathrm{mV} \mathrm{s}^{-1}$.

A further significant observation is that, upon removing the electrode from solution, polishing to a bright finish, and replacing in $1.0 \mathrm{M} \mathrm{NaOH}$, it was impossible to again record a voltammetric profile similar to the first cycle of Fig. 1. 
Instead the profile was more reminiscent of the second cycle - in fact the only way to recapture a voltammogram, similar to the first cycle of Fig. 1, was to completely destroy the electrode surface by thorough abrasion with rough grit paper, followed by re-preparation of the electrode. This behaviour suggests that upon the initial passivation of a $\mathrm{Fe}$ electrode in alkaline solution, a strongly bound thin compact oxide layer is formed, that is resistant to subsequent removal by mechanical polishing. When the apparently bright electrode is again subjected to potential cycling following such polishing, the passivation process effectively "resumes" in a manner similar to that characterised by the second cycle of Fig. 1.

\section{Mechanism of thick multilayer hydrous oxide film growth under potential cycling conditions}

Although the detailed mechanism of reaction under potential cycling conditions is not yet completely resolved, it is now well established that the initial oxidation process involves the formation of $\mathrm{OH}$ and $\mathrm{O}$ radicals which adsorb, initially in a reversible manner on the metal surface. With increasing degree of surface coverage, the adsorption assumes a more irreversible character, accompanied by the formation, via a place exchange mechanism, of a thin, largely anhydrous compact passivating oxide layer of tentative composition $\mathrm{FeO}$ or $\mathrm{Fe}(\mathrm{OH})_{2}$. This irreversibility is indicated by the observation that the voltammetric peak potentials vary in a quasi-Tafel manner with sweep rate, ${ }^{12}$ when the former are recorded during the initial potential sweep. Under conventional steady state anodization conditions such layers are usually of limited thickness, as the activation energy for ion migration in the compact film is generally quite large.

Even though it is directly produced in the initial electrochemical oxidation process, the anhydrous film is probably not the most stable oxidation product in an aqueous medium but it may be regarded as an intermediate or metastable product in the formation of a hydrous oxide layer. In the anhydrous film ions are held in a rigid manner in an extended network of polar covalent bonds, which drastically reduce ion transport through, and consequently extension of, the surface layer. The next stage of the film thickening process, the hydration process, is generally slow, because as in phase transformation reactions, it involves the rupture of primary coordination metal-oxygen bonds. The marked dependence (reported previously $^{12}$ by us) of oxide growth rate on the lower limit of the potential sweep is indicative of the important role that partial reduction of the anhydrous compact oxide plays in the production of a thick polymeric deposit. It appears that this partial reduction of the compact layer facilitates rearrangement of oxycation species at the metal surface, leaving it in a somewhat disrupted state. On subsequent re-oxidation of the partially reduced metal surface, the compact layer is restored, but its outer region is present in a more dispersed form. On further reduction the latter material becomes incorporated into the hydrated outer layer. The outer layer is reduced much less readily than the anhydrous compact layer, and thus, during potential cycling, it accumulates on the electrode surface as a gradually thickening film.

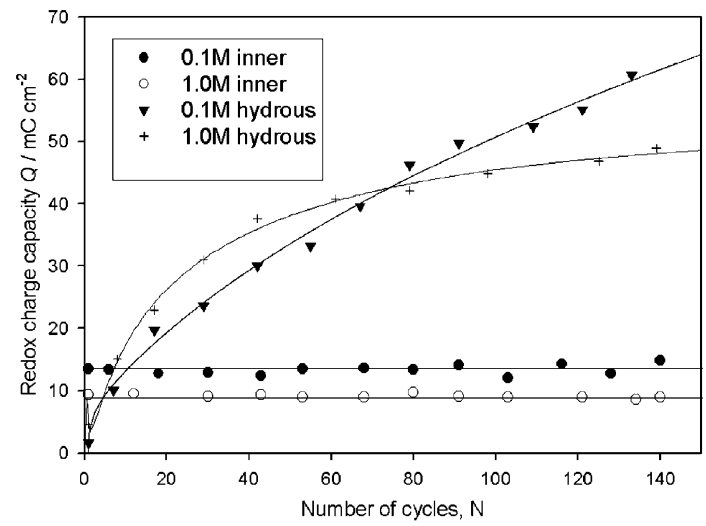

Fig. 4 Variation of the charge capacity $Q$ associated with the outer hydrated oxide film (evaluated by integration of the A3 peak) and the inner compact oxide film (based on integration of the $\mathrm{C} 1$ peak) with increasing number of cycles, $N$, as a function of $\mathrm{OH}^{-}$ion concentration at $25{ }^{\circ} \mathrm{C}$. The oxide films were grown by repetitive potential cycling between -1.425 and $0.325 \mathrm{~V}$ at a sweep rate of $0.35 \mathrm{~V} \mathrm{~s}^{-1}$.

An interesting series of results are outlined in Fig. 4 and 5. The variation, is outlined in Fig. 4, of the film redox charge capacity $Q$ for the outer hydrous and inner anhydrous oxide layers as a function of the number of growth cycles $N$ at two different hydroxide ion concentrations $\left(\left[\mathrm{OH}^{-}\right]=0.1\right.$ and $1.0 \mathrm{M}$ ). A number of important features are to be noted. Firstly the rate of hydrous oxide growth, $\mathrm{d} Q / \mathrm{d} N$, is dependent on the electrolyte concentration. During the initial stages of layer growth ( small $N$ ), the growth rate is more rapid in the more concentrated as opposed to the more dilute hydroxide solution. However the growth rate decreases quite rapidly with increasing $N$ in the more concentrated medium, whereas the growth rate is little affected with increasing $N$ in the more dilute solution. Indeed, significantly larger redox capacities may be observed at a given $N$ value in the dilute solution, once a certain threshold cycle number ( $c a$. 70) is exceeded. In contrast the inner compact oxide charge capacity does not vary with increasing number of cycles, but does depend on the hydroxide ion concentration, slightly greater $Q$ values being observed for the more dilute alkaline solution.

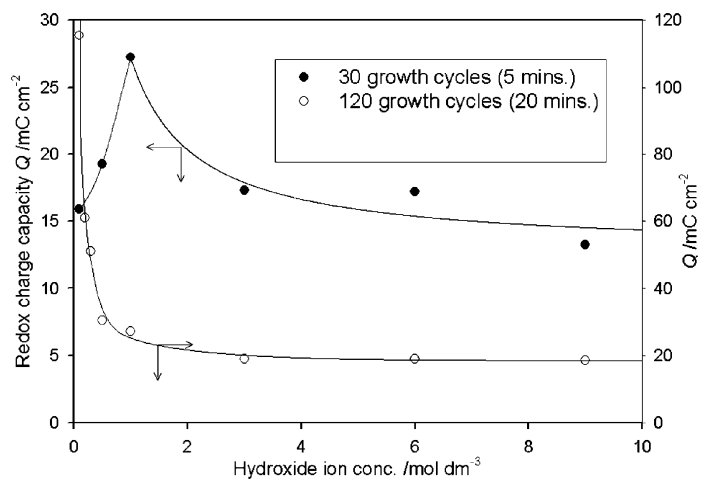

Fig. 5 Variation of multi-layer oxide growth with hydroxide ion concentration for multi-cycled iron electrodes $(-1.425$ to $0.325 \mathrm{~V}$, $0.35 \mathrm{~V} \mathrm{~s}^{-1}$ at $25{ }^{\circ} \mathrm{C}$ ) with different growth times. $Q$ was evaluated by integration of the $\mathrm{A} 3$ voltammetric peak. 
The variation of the extent of hydrous oxide growth (expressed again in terms of redox charge capacity recorded after a given number of potential cycles) with hydroxide ion concentration is illustrated in Fig. 5. Two sets of experiments are outlined. In the first, the layer was grown at a constant sweep rate of $350 \mathrm{mV} \mathrm{s}^{-1}$ for 30 cycles (this corresponds to 5 min activation) in differing concentrations of hydroxide, whereas in the second series of experiments, the number of growth cycles was increased to 120 (corresponding to $20 \mathrm{~min}$ activation at $350 \mathrm{mV} \mathrm{s}^{-1}$ ). Markedly differing behaviour is observed in the two sets of experiments. In the case of layers grown for a shorter activation time, a maximum charge capacity is observed when $\left[\mathrm{OH}^{-}\right]=1.0 \mathrm{M}$. In contrast, with layers grown for the longer activation time, a sharp decrease in charge capacity with increasing hydroxide ion concentration is observed. Hence in this latter situation the layer exhibits greatest electroactivity in the most dilute hydroxide solution. Note that $Q$ values were always determined at a slow analytical sweep rate $\left(40 \mathrm{mV} \mathrm{s}^{-1}\right)$ to ensure that one had maximum titration of all redox centres in the layer, and so the integrated voltammetric response accurately reflected the amount of redox active sites in the hydrous layer.

The decrease in oxide growth rate with time (or equivalently with increasing film thickness) can be attributed to the increasing inhibition of water and hydroxide ion transfer to the inner region of the oxide layer, with increasing hydrous oxide thickness. The data outlined in Fig. 4 and 5 indicate that the effect is more marked with increasing base concentration. Evidently, increased hydroxide ion activity suppresses hydroxide dissociation and/or favours adsorption of this species. This will result in the inhibition of crystallization of the hydrous oxide layer, and the resulting more amorphous film will be more effective in excluding water from the inner region of the oxide film, thereby inhibiting the growth of the microdisperse hydrous layer.

\section{Analysis of the redox switching reaction in the hydrous layer}

The variation of the hydrous oxide charge capacity, $Q$ (which is proportional to the redox charge capacity, $C$, defined for electroactive polymer films in the work of Chidsey and Murray ${ }^{28-31}$ ) with analytical sweep rate is outlined in Fig. 6.

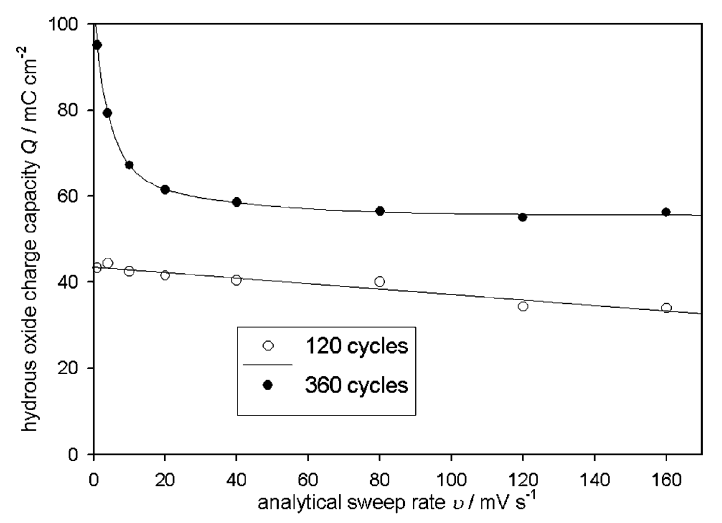

Fig. 6 Variation of charge capacity $Q$ (evaluated by integration of the A3 voltammetric peak) with analytical sweep rate for iron oxide films grown under potential cycling conditions $(-1.425$ to $0.325 \mathrm{~V}$, $0.35 \mathrm{~V} \mathrm{~s}^{-1}$ ) for either 120 or 360 cycles in $1 \mathrm{M} \mathrm{NaOH}$ at $25^{\circ} \mathrm{C}$.
The recorded $Q$ values for a reasonably thin layer (120 growth cycles) decreased slightly, and in an approximately linear manner, on increasing the rate, $\nu$, of the analytical scan. With a somewhat thicker film (360 cycles) the $Q$ values decreased by nearly $50 \%$ as the analytical scan rate was increased from 1 to $50 \mathrm{mV} \mathrm{s}^{-1}$. Little subsequent decrease in the charge capacity values was observed on further increase in sweep rate.

These results may be rationalised in terms of a simple diffusional model. With thinner films there is sufficient time at normal sweep rates for the redox reaction to extend to virtually all regions of the dispersed hydrous layer, i.e. a situation of Nernstian equilibrium prevails and the redox charge capacity will be effectively independent of sweep rate. However with thicker films there is not enough time (apart from at very low scan rates) for the redox reaction to propagate throughout the entire extent of the dispersed hydrated region. Thus the charge capacity values drop dramatically as the analytical sweep rate is increased. The increased charge capacity at very low sweep rates is possibly due to ion penetration into the more anhydrous compact material in the inner regions of the oxide film. Hence for thicker films, much of the material is inert at normal analytical sweep rates, with respect to redox switching activity. However for thin films the converse holds: a substantial portion of the film is active. Obviously with these oxide systems, one cannot automatically use charge capacity values as a measure of layer thickness. However such an approach may be used if a suitable pre-treatment protocol can be devised to activate the entire film. Such concepts have also been developed by Trasatti and co-workers ${ }^{32}$ who have differentiated between an "inner" or less accessible and "outer" or more accessible active surface in their discussion of the redox chemistry exhibited by thermally prepared $\mathrm{RuO}_{2}$ electrodes in aqueous acid and base solutions.

We now consider the results of a series of experiments, conducted to quantify the rate of charge percolation through the hydrated layer. The redox switching reaction (associated with the $\mathrm{A} 3 / \mathrm{C} 2$ voltammetric peaks) reflects the change in oxidation state of the film as a result of a potential perturbation. Redox centres immediately adjacent to the support electrode are directly affected by the electrode potential, whereas charge is further propagated along the oxy-iron polymer strands in the hydrous layer via a sequence of electron self exchange reactions between neighbouring oxy-metal sites. This process is envisaged to be analogous to redox conduction exhibited by electroactive polymer films. In the simplest terms this electron "hopping" may be modelled in terms of a diffusional process, and so the charge percolation rate may be quantified in terms of a charge transport diffusion coefficient, $D_{\mathrm{CT}}$. In the case of hydrous iron oxide, the latter may reflect either the electron hopping rate or the diffusion of $\mathrm{OH}^{-}$(or equivalently $\mathrm{H}_{3} \mathrm{O}^{+}$) ions via a rapid Grotthuss type mechanism. The charge transport diffusion coefficient may be quantitatively estimated using cyclic voltammetry.

In the present work we utilise the mathematical formalism of Aoki and co-workers ${ }^{33}$ to derive an expression for $D_{\mathrm{CT}}$. Transport information may be readily extracted from an analysis of the shape of the voltammetric response as a function of sweep rate, $\nu$. In particular, the peak current, $i_{\mathrm{p}}$, 
representing the main redox switching process in the hydrated layer varies with $\nu$ according to,

$$
i_{\mathrm{p}}=0.446 n F A\left\{\frac{\Gamma D_{\mathrm{CT}}}{L^{2}}\right\} W^{1 / 2} \tanh Y
$$

where,

$$
W=\frac{n F L^{2} \nu}{D_{\mathrm{CT}} R T}, \quad Y=0.56 W^{1 / 2}+0.05 W
$$

In the latter expressions, $n, F, A$ and $\Gamma$ denote, respectively, the number of electrons transferred in the redox process, the Faraday constant, the geometric area of the electrode and the surface coverage of the active oxy-iron groups in the hydrous layer. The latter quantity is related to the charge capacity $Q$ and the redox site concentration $c_{\Sigma}$ via, $\Gamma=c_{\Sigma} L=Q / n F A$, where $L$ denotes the layer thickness.

Two limiting forms of the general expression outlined in eqn (2) may be identified. For low values of sweep rate corresponding to small $W$, we can set tanh $Y \approx Y$ in eqn (2), to obtain,

$$
i_{\mathrm{p}}=\frac{n^{2} F^{2} A \Gamma \nu}{4 R T}
$$

whereas at large sweep rates corresponding to large $W$ values, we set $\tanh Y \approx 1$ and obtain:

$$
i_{\mathrm{p}}=0.446\left\{\frac{(n F)^{3}}{R T}\right\}^{1 / 2} A D_{\mathrm{CT}}^{1 / 2} c_{\Sigma} \nu^{1 / 2}
$$

As previously noted, concentration polarization effects, due to incomplete titration of redox sites within the dispersed hydrated layer, are manifest at larger sweep rates. Diffusion coefficients may only be evaluated in this region. The $i_{\mathrm{p}} / \nu^{1 / 2}$ proportionality can be most readily obtained at reasonable values of sweep rate for thick layers, whereas the $i_{\mathrm{p}} / \nu$ proportionality (suggesting the operation of Nernstian equilibrium throughout the dispersed layer during redox switching) will be observed over an extended range of sweep rates with thin layers. These general conclusions are illustrated in Fig. 7 and 8 .

We note from the data for thin films illustrated in Fig. 7(a), that excellent linearity is observed between the peak current and scan rate, both for the hydrous oxide peaks A3 and C2, and for the compact oxide reduction peak $\mathrm{C} 1$, over an extended scan rate window. This observation is confirmed in the double logarithmic analysis of the data (Fig. 7(b)), where the slopes of greater than 0.8 are noted for the A3 and C2 peaks. In contrast data obtained for thicker layers is outlined in Fig. 8. In this case we obtain good linearity (except at relatively low $\nu$ ) when $i_{\mathrm{p}}$ is plotted versus $\nu^{1 / 2}$. The double logarithmic analysis of the data (Fig. 8(b)) is particularly interesting in that a dual slope behaviour is observed (gradient in region A: 0.97; gradient in region B: 0.64$)$. The sweep rate at which concentration polarization effects become important may be readily discerned from the break point in this "dog's leg" curve. Transport information in the form of a $D_{\mathrm{CT}}$ value may be extracted from the data in region $\mathrm{B}$.

The Randles-Sevcik plots illustrated in Fig. 8(a) yield gradients of $0.133 \mathrm{AV}^{-1 / 2} \mathrm{~s}^{1 / 2}$ and $0.167 \mathrm{AV}^{-1 / 2} \mathrm{~s}^{1 / 2}$ for the
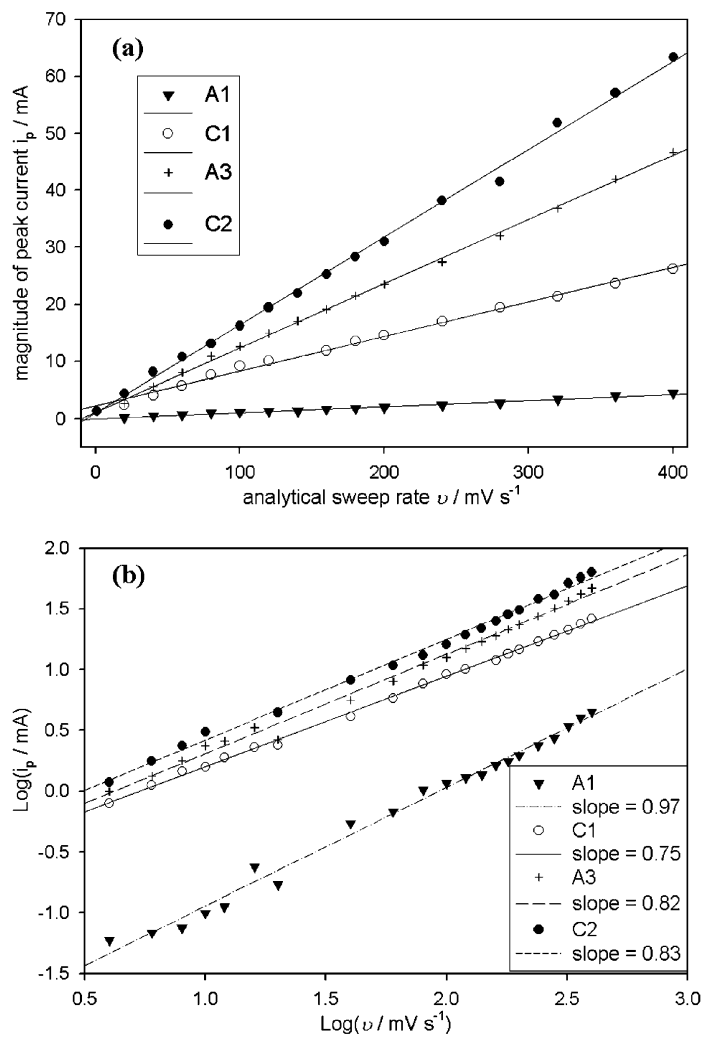

Fig. 7 (a) Variation of voltammetric peak current with sweep rate for a multicycled iron electrode ( 30 cycles, -1.425 to $0.325 \mathrm{~V}, 0.35 \mathrm{~V} \mathrm{~s}^{-1}$ ) in $1 \mathrm{M} \mathrm{NaOH}$ at $25{ }^{\circ} \mathrm{C}$. (b) $\log i_{\mathrm{p}} / \log \nu$ plot of the data outlined in Fig. 7(a).

peaks $\mathrm{A} 3$ and $\mathrm{C} 2$, respectively. The concentration of redox sites in the oxide layer is effectively given by the expression $c_{\Sigma}=\rho / M$, where $\rho$ denotes the density of the hydrous material and $M$ represents the molar mass of the fundamental repeat unit of the hydrated oxy-iron polymer. For the anodic process (peak A3) if the composition of the reduced state is assumed to be $\left[\mathrm{Fe}_{2}(\mathrm{OH})_{6}\left(\mathrm{OH}_{2}\right)_{3}\right]^{2-}$ with molar mass $267 \mathrm{~g} \mathrm{~mol}^{-1}$, and if we assume that the density $\rho$ is given by that for $\mathrm{Fe}(\mathrm{OH})_{2}{ }^{34}$ which is $3.4 \mathrm{~g} \mathrm{~cm}^{-3}$, then given that $n=2$ for the redox process (recall eqn (1)), one can evaluate (from eqn (5)) that $D_{\mathrm{CT}}=1.88 \times 10^{-10} \mathrm{~cm}^{2} \mathrm{~s}^{-1}$. For the corresponding reduction process (peak $\mathrm{C} 2$ ), where the oxidised repeat unit is assigned the composition $\left[\mathrm{Fe}_{2} \mathrm{O}_{3}(\mathrm{OH})_{3}\left(\mathrm{OH}_{2}\right)_{3}\right]^{3-}$ we have $M=265 \mathrm{~g} \mathrm{~mol}^{-1}$. It is known ${ }^{35}$ that the density of $\mathrm{Fe}_{2} \mathrm{O}_{3}$. $\mathrm{nH}_{2} \mathrm{O}$ is in the range 2.4-3.6 $\mathrm{g} \mathrm{cm}^{-3}$ depending on the degree of hydration. We assume a mean value of $\sim 3 \mathrm{~g} \mathrm{~cm}^{-3}$. Hence again, for $n=2$ one obtains from the Randles-Sevcik plot (Fig. 8) that $D_{\mathrm{CT}}=3.77 \times 10^{-10} \mathrm{~cm}^{2} \mathrm{~s}^{-1}$. Hence the average charge transfer diffusion coefficient obtained from these voltammetric experiments conducted on thick oxide layers is $2.8 \times 10^{-10} \mathrm{~cm}^{2} \mathrm{~s}^{-1}$. The latter value is not unreasonable compared with those obtained for electroactive polymer modified electrodes such as polyaniline $\left(D_{\mathrm{CT}}=3 \times 10^{-9} \mathrm{~cm}^{2} \mathrm{~s}^{-1}\right)^{36-38}$ and poly(pyrrole) $\left(D_{\mathrm{CT}}=1 \times 10^{-8} \mathrm{~cm}^{2} \mathrm{~s}^{-1}\right) \cdot{ }^{39,40}$

In view of the assumptions made with regard to the density and surface area of the oxide, the value reported for $D_{\mathrm{CT}}$ is only approximate. Furthermore in view of the nature of the hydrous film, with charge percolation occurring through 

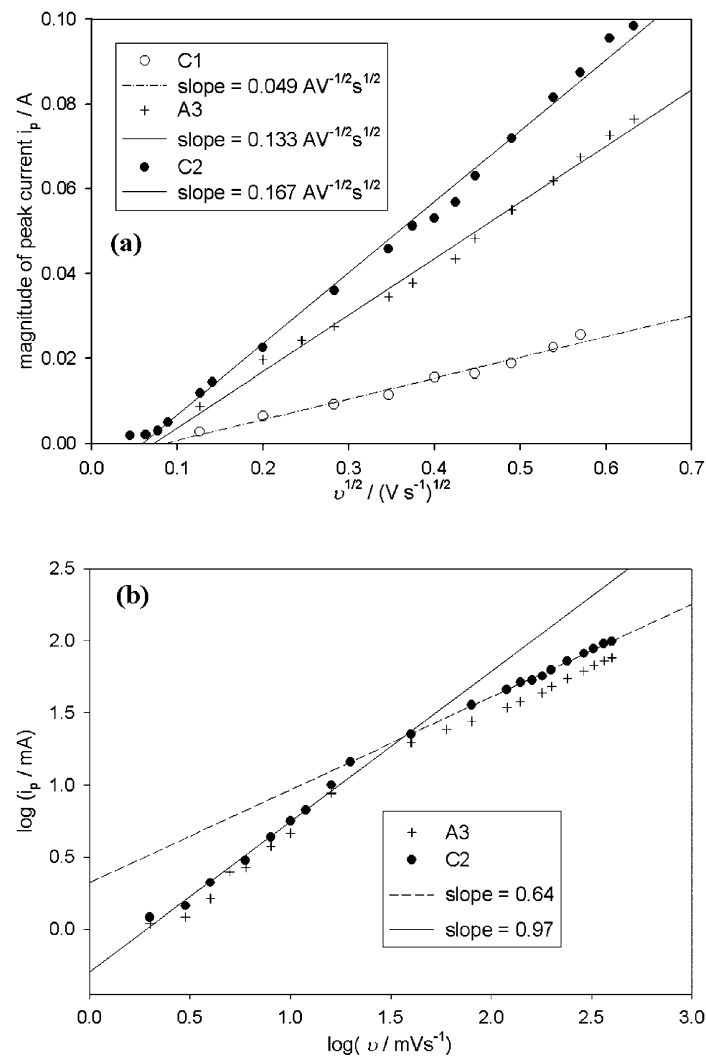

Fig. 8 (a) Variation of voltammetric peak current with sweep rate for a multicycled iron electrode ( 240 cycles, -1.425 to $0.325 \mathrm{~V}, 0.35 \mathrm{~V} \mathrm{~s}^{-1}$ ) in $1 \mathrm{M} \mathrm{NaOH}$ at $25^{\circ} \mathrm{C}$. (b) $\log i_{\mathrm{p}} / \log \nu$ plot of the data outlined in Fig. 8(a).

regions of varying oxide, solvent and electrolyte content, the value quoted must be regarded as a macroscopic average diffusion coefficient for transport through these various regions. It is also difficult to unambiguously identify the rate controlling transport process occurring within the layer during redox switching. The diffusion coefficient may correspond to ionic transport, electron self exchange between neighbouring sites, or the segmental motion of polymer chains antecedent to the latter processes. A definite assignment can only be obtained if the activation energy for charge percolation is determined. Such measurements are currently being conducted in our laboratory and the results will be presented in another communication.

\section{Oxygen evolution reaction steady state polarisation measurements}

Our investigations of the electrocatalytic properties of hydrated iron oxyhydroxide layers have focused on the technologically important oxygen evolution reaction (OER). Recent reviews of the OER, include those due to Kinoshita, ${ }^{41}$ Bockris and $\mathrm{Khan}^{42}$ and Gattrell and MacDougall. ${ }^{43}$ It is worth noting that in alkaline solution, oxygen evolution may be described via the following stoichiometric equation:

$$
4 \mathrm{OH}^{-} \rightarrow \mathrm{O}_{2}+2 \mathrm{H}_{2} \mathrm{O}+4 \mathrm{e}^{-}
$$

A comparison is presented in Fig. 9, of $i R$ corrected, OER steady state polarisation curves recorded in $1.0 \mathrm{M} \mathrm{NaOH}$

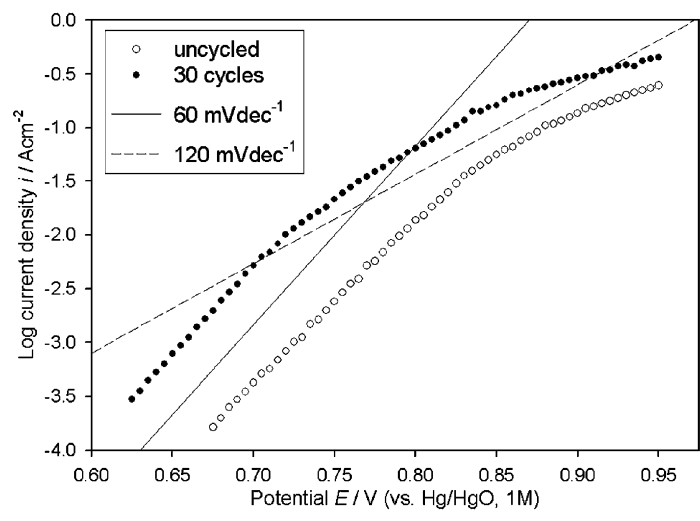

Fig. 9 Comparison of $i R$-corrected, oxygen evolution steady state polarisation curves for a multi-cycled ( 30 cycles, -1.425 to $0.325 \mathrm{~V}$, $0.35 \mathrm{~V} \mathrm{~s}^{-1}$ ) and an uncycled iron electrode in $1.0 \mathrm{M} \mathrm{NaOH}$ at $25^{\circ} \mathrm{C}$.

solution, for an uncycled and a multi-cycled polycrystalline iron electrode. The multi-cycled electrode was prepared by cycling the electrode potential between limits of -1.425 and $0.325 \mathrm{~V}$ (30 cycles) in $1.0 \mathrm{M} \mathrm{NaOH}$ at a sweep rate of $0.35 \mathrm{~V} \mathrm{~s}^{-1}$. The variation of the hydrous oxide charge capacity $Q$ with the number of cycles, for oxide growth between these limits and at this sweep rate, was presented in Fig. 4. In agreement with that data, a hydrous oxide charge capacity of $Q \approx 30 \mathrm{mC} \mathrm{cm}^{-2}$ was obtained by the integration of the A3 anodic peak of an analytical CV (as before, between -1.275 and $0.725 \mathrm{~V}$ at $0.04 \mathrm{~V} \mathrm{~s}^{-1}$ ) recorded in the growth solution following the completion of the 30 growth cycles.

The Tafel plots of Fig. 9 reproduce a result that was first published by us some time ago, ${ }^{11}$ namely that the oxygen evolution performance of a multi-cycled $\mathrm{Fe}$ electrode is significantly enhanced relative to an uncycled electrode. In that preliminary communication, the rate of the OER in $1 \mathrm{M}$ $\mathrm{NaOH}$ was observed to increase by a factor of ten for a multicycled Fe electrode (as in the present work, $Q \approx 30 \mathrm{mC} \mathrm{cm}^{-2}$ ) by comparison with an uncycled anode, for potentials associated with the lower straight line Tafel region. A similar conclusion can be drawn from the data of Fig. 9. Indeed the enhanced OER catalytic performance of a multicycled iron electrode compared to an uncycled anode, can even be appreciated by comparing the onset potentials of the rising edge of the OER current density appears in the 1st and 100th cycles of Fig. 2. It should also be pointed out at this stage that the OER does not occur on a metallic surface in the case of the uncycled Fe electrode-upon introduction to alkaline solution and application of an anodic polarisation regime, a passive oxide will form on the metal surface, and it is at the surface of this oxide that electrocatalysis of the OER occurs. As we discussed previously, ${ }^{11}$ it is likely that the principal reason behind the increase in OER electrocatalytic activity, on going from an uncycled to a multi-cycled $\mathrm{Fe}$ anode, is related to the significant increase in oxyiron-solution contact, which will accompany the thickening (with potential cycling) of the porous, dispersed, outer hydrous oxide.

The effect of solution $\mathrm{OH}^{-}$ion concentration (at a constant hydrous oxide layer thickness) on the rate and kinetics of the OER is detailed in Fig. 10. For each experiment, the oxide layer was grown for 30 cycles in $1.0 \mathrm{M} \mathrm{NaOH}$ as described 


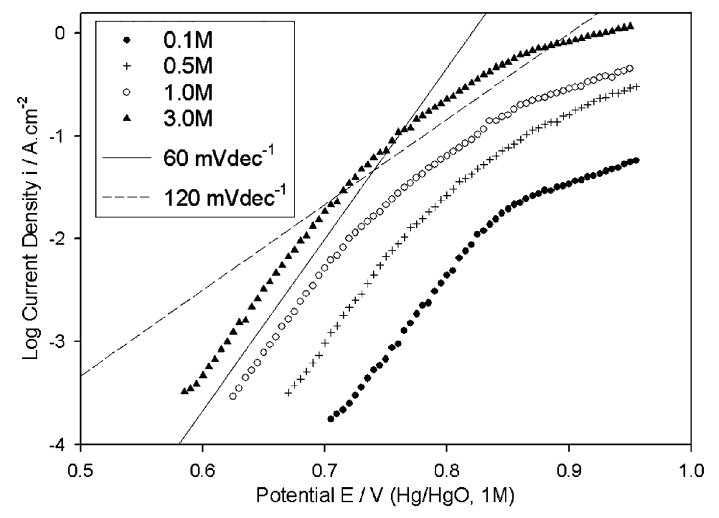

Fig. $10 i R$-corrected steady state polarisation curves recorded in the direction of increasing potential for a for a multi-cycled (30 cycles, -1.425 to $0.325 \mathrm{~V}, 0.35 \mathrm{~V} \mathrm{~s}^{-1}$ ) iron electrode in $\mathrm{NaOH}$ solutions of various concentration.

above, and the electrode was then transferred to the test solution. The interesting features of the data of Fig. 9 and 10 are as follows. Firstly, a Tafel slope, $b$, of $c a .60 \mathrm{mV} \mathrm{dec}{ }^{-1}$ $\left(\approx 2.303 \times R T / F\right.$ at $\left.25{ }^{\circ} \mathrm{C}\right)$ is observed at lower potentials, regardless of base concentration and for both the multi-cycled and uncycled electrodes. This indicates that in this region of potential, the nature of the rate determining step (RDS) remains invariant with respect to oxide thickness and nature (i.e. thick hydrous oxide $v s$. thinner passive oxide) or $\mathrm{OH}^{-}$ion concentration. There is also evidence for a second Tafel region (slope ca. $120 \mathrm{mV} \mathrm{dec}^{-1} \approx 2.303 \times 2 R T / F$ at $25^{\circ} \mathrm{C}$ ) at higher overpotentials. This observation must arise naturally from the quantitative analysis of any proposed mechanistic scheme. Deviations from ideal Tafel behaviour are observed at still higher potentials. This presumably arises due to the onset of mass transport limitations.

A reaction order plot with respect to $\mathrm{OH}^{-}$ion activity (calculated from literature values ${ }^{44}$ for the mean ionic activity coefficients, $\left.\gamma_{ \pm}\right)$is constructed in Fig. 11 for a potential $(0.725 \mathrm{~V})$ located in the lower Tafel slope region. The significant feature here is that a non-integral reaction order, $m_{\mathrm{OH}-}$, of $c a .3 / 2$ is obtained. Similar numerical values for the reaction order are obtained for plots derived from current density data recorded at other potentials in the low Tafel slope region. In contrast, we also note from Fig. 11 that a reaction

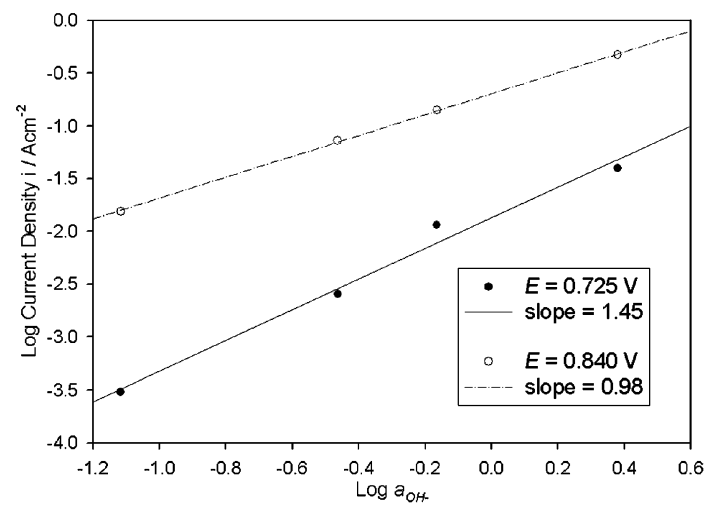

Fig. 11 Reaction order plots based upon the polarisation curves of Fig. 10, at the indicated potentials. order of approximately unity is obtained for data extracted from the higher Tafel slope region $(0.840 \mathrm{~V})$.

It must be commented at this point, that the OER Tafel slope behaviour outlined in Fig. 9 for the uncycled Fe anode differs somewhat from that which we have observed (and reported elsewhere ${ }^{45}$ ) for freshly prepared, bright polycrystalline iron electrodes in alkaline solution. This probably arises due to electrode ageing, since the same Fe electrode was used in the experiments detailed in Fig. 4-8, prior to its utilisation in the OER steady state polarisation study.

Indeed, we have recorded similar oxygen evolution kinetic data for an aged polycrystalline Fe electrode that was utilised in many OER steady state polarisation experiments ( $>40$ over the course of four months), but was never subject to potential multi-cycling. In order to obtain reproducible Tafel characteristics for this "type" of anode (which will henceforth be referred to as an "aged" Fe electrode), a pre-treatment regime was devised consisting of pre-reduction at $-1.3 \mathrm{~V}$ for $15 \mathrm{~min}$ in 1.0 $\mathrm{M} \mathrm{NaOH}$, followed by one voltammetric cycle between the limits of -1.175 and $0.625 \mathrm{~V}$ in the same solution at a scan rate of $40 \mathrm{mV} \mathrm{s}^{-1}$. A typical profile of the latter cycle is presented in Fig. 12. Oxygen evolution steady state polarisation curves for the aged electrode in $\mathrm{NaOH}$ solutions of various concentrations are depicted in Fig. 13. As with the data of Fig. 9 and 10, it is obvious that the polarisation curves of Fig. 13 are characterised by a Tafel slope of $c a .60 \mathrm{mV} \mathrm{dec}^{-1}$ at lower potentials and a somewhat less well defined slope of ca. $120 \mathrm{mV} \mathrm{dec}{ }^{-1}$ at higher overpotentials. Reaction order plots for potentials associated with the aforementioned Tafel regions are presented in Fig. 14. Again $m_{\mathrm{OH}-} \approx 3 / 2$ is suggested for the $c a .60 \mathrm{mV} \mathrm{dec}{ }^{-1}$ region, while a reaction order approaching unity is connected with the higher Tafel slope. Thus it would seem reasonable to conclude that the same OER mechanism prevails for the uncycled (Fig. 9), multicyled hydrous oxide covered (Fig. 9 and 10), and aged, passive oxide covered (Fig. 13) iron electrodes in aqueous alkaline solution.

The distorted form of the characteristic CV (Fig. 12) of the aged Fe electrode (with its large background charge at potentials immediately below those associated with significant oxygen evolution), in comparison to the voltammograms of Fig. 1 and 2, merits some comment. The profile of Fig. 12 is probably characteristic of a more disorganised and hydrated

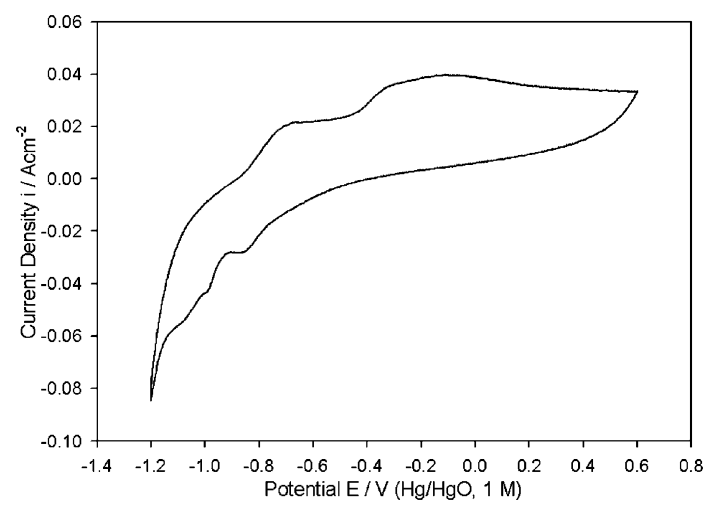

Fig. 12 Typical voltammetric profile for an aged iron electrode (see text for more details) recorded in $1.0 \mathrm{M} \mathrm{NaOH}$ at $40 \mathrm{mV} \mathrm{s}^{-1}$. 


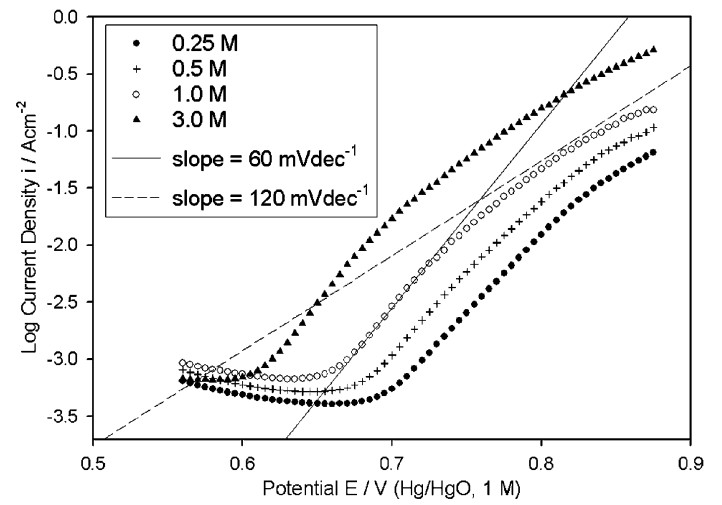

Fig. $13 i R$-corrected steady state polarisation curves recorded in the direction of increasing potential for an aged iron electrode (as characterised voltammetrically in Fig. 12) in $\mathrm{NaOH}$ solutions of various concentration.

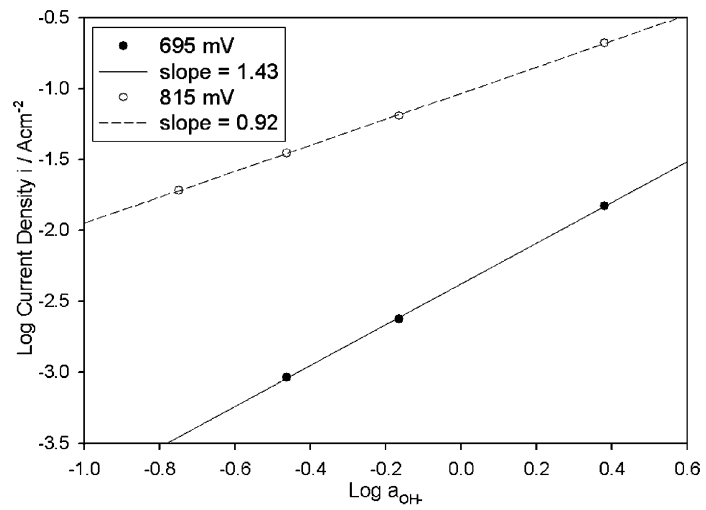

Fig. 14 Reaction order plots based upon the polarisation curves of Fig. 13, at the indicated potentials.

electrode surface than is found for fresher Fe anodes. This can be envisaged to arise as a cumulative result of a continuous cycle, over the electrode service life, of mechanical polishing and subsequent re-passivation of surfaces containing some residual oxide material. A practical implication of the large background charge associated with the surface electrochemistry of the aged Fe electrode, is the rather limited range of current density (or equivalently overpotential) over which the $\sim 60 \mathrm{mV} \mathrm{dec}{ }^{-1}$ OER Tafel region can be experimentally accessed - only little more than one decade of current density from $\sim 10^{-3} \mathrm{~A} \mathrm{~cm}^{-2}$ upwards for the $1.0 \mathrm{M}$ curve of Fig. 13 . This limited potential window causes difficulties in the construction of associated reaction order plots. The plot for the lower Tafel region in Fig. 14 is based upon only the polarisation data for the upper three $\mathrm{OH}^{-}$ion concentrations utilised, since, as is obvious from Fig. 13, the characteristic for the 3.0 M solution has already passed through this $\sim 60 \mathrm{mV} \mathrm{dec}^{-1}$ region at the potential for which a significant OER current appears for the $0.25 \mathrm{M}$ solution.

\section{E.I.S. measurements}

A series of electrochemical impedance spectroscopy (EIS) measurements, performed successively in the direction of increasing potential for the aged $\mathrm{Fe}$ electrode in $1.0 \mathrm{M} \mathrm{NaOH}$
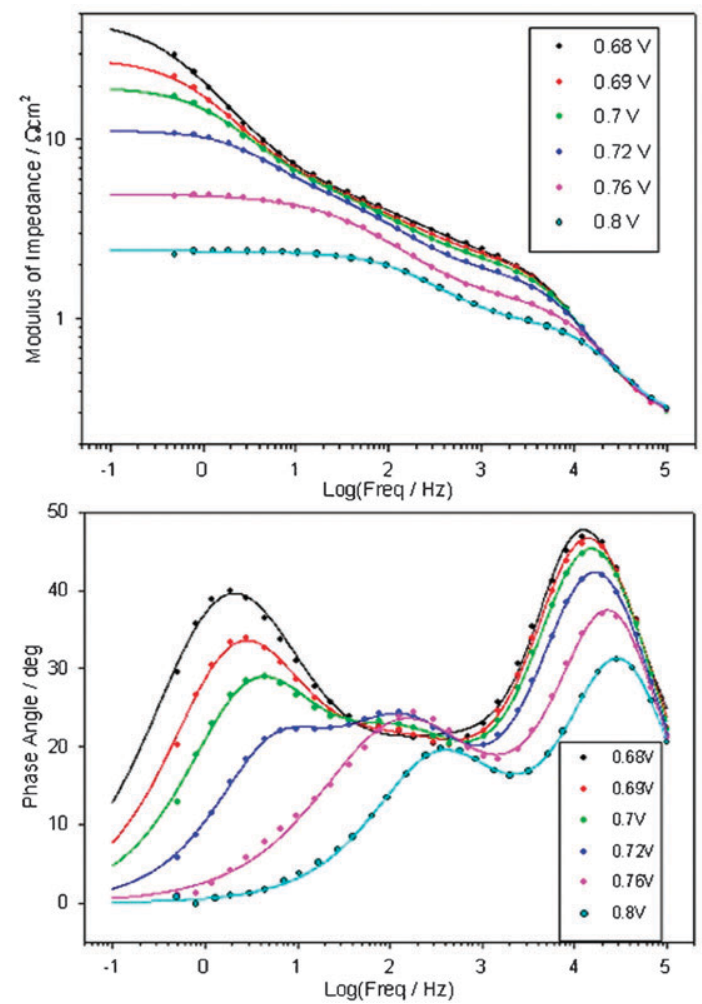

Fig. 15 Bode plots recorded at various potentials within the region of significant OER current density for an aged $\mathrm{Fe}$ electrode in $1.0 \mathrm{M}$ $\mathrm{NaOH}$ solution. The raw data is represented by the circles, while the continuous lines plot the optimised transfer functions for the relevant equivalent circuit model (Fig. 17).

solution are presented in the Bode format in Fig. 15 or, equivalently, in the Nyquist (complex plane) representation in Fig. 16. A detailed discussion of the impedance responses of oxidised $\mathrm{Fe}, \mathrm{Ni}$ and $\mathrm{Co}$ anodes in the oxygen evolution potential region and the appropriate choice of equivalent circuit model will be presented elsewhere ${ }^{46}$ - here we limit our treatment to aspects of the EIS data related to the kinetics of the OER.
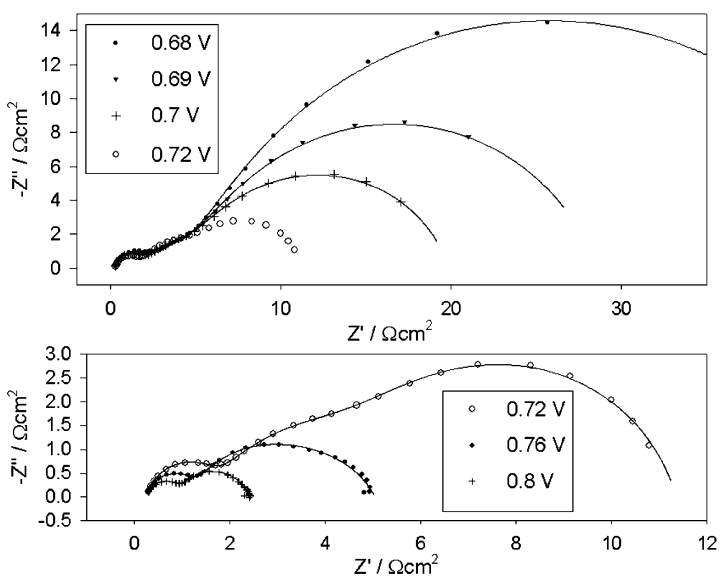

Fig. 16 Nyquist representations of the impedance data of Fig. 15. Again the continuous lines are generated by the results of the CNLS fitting process, while the discrete points represent the raw data. 

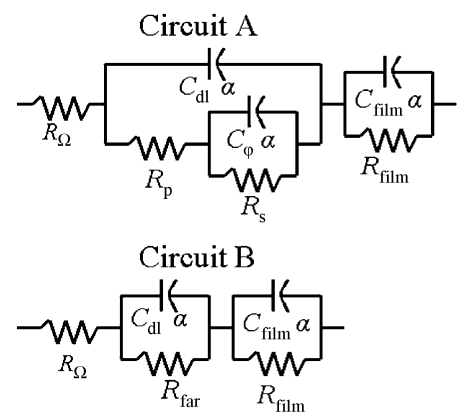

Fig. 17 Equivalent circuits used in the CNLS fitting of the impedance data of Fig. 15 and 16. Circuit A reduces to Circuit B at higher overpotentials and the latter is used for modelling the data recorded at 0.76 and $0.8 \mathrm{~V}$. The meaning of $R_{\mathrm{far}}$ is discussed below (see eqn (9)).

Using the Thales SIM software, the raw impedance data was fitted to the equivalent circuit models depicted in Fig. 17. The various circuit elements have the following significance; $R_{\Omega}$ represents the uncompensated electrolyte resistance, $C_{\text {film }}$ and $R_{\text {film }}$ are respectively related to the dielectric properties and the resistivity of the oxide film, $C_{\mathrm{d} 1}$ models the double layer capacitance, the resistive elements $R_{\mathrm{p}}$ and $R_{\mathrm{S}}$ are related to the kinetics of the interfacial charge transfer reaction, ${ }^{47}$ while $C_{\phi}$ is the value of a capacitor, which in parallel with the resistance, $R_{\mathrm{s}}$, models correctly the relaxation of the charge associated with the adsorbed intermediate(s). ${ }^{47}$

It is noteworthy that the Nyquist plot semicircles of Fig. 16 are of a depressed nature which is indicative of frequency dispersion in the various capacitive responses. Particularly with respect to the double layer capacitance, such frequency dispersion is generally believed ${ }^{48}$ to arise owing to surface inhomogeneity and roughness. In order to simulate the experimental frequency dispersion, constant phase elements (CPEs) are used in the equivalent circuit models of Fig. 17 in place of pure capacitors. In this approach, the impedance, $Z_{\mathrm{CPE}}$, of a capacitive process displaying frequency dispersion is expressed as:

$$
Z_{\mathrm{CPE}}=A(j \omega)^{-\alpha}
$$

In eqn (6), $A=1 / C_{\alpha=1}$, where $C_{\alpha=1}$ is the value of the capacitance in the absence of frequency dispersion, and $\alpha$ is an exponent ( $\alpha \leq 1$ for a physically reasonable situation) equal to unity in the case of an ideal capacitor. The result of a CNLS fitting of raw impedance data to a CPE using the SIM program, is an output in the form of optimised values for $C_{\alpha=1}$ and $\alpha$.

It is obvious from the phase angle $v s$. log frequency plots of Fig. 15, that, as the applied potential is increased, the low frequency $\left(C_{\phi}\right)$ capacitive contribution diminishes, as indicated by the decrease in the observed maximum phase angle, in the $0-1 \mathrm{~Hz}$. frequency region. In particular, for the spectra recorded at $E=0.76$ and $0.8 \mathrm{~V}$, the low frequency adsorption pseudo-capacitance is negligible in comparison to the double layer capacitance and the appropriate equivalent circuit model reduces to circuit B (Fig. 17). Fitting parameters can still be obtained for $C_{\phi}$ at these higher overpotentials, however the fitting program output indicates that they have little significance. The optimised values of the equivalent circuit parameters, obtained by the CNLS fitting of the raw data of Fig. 15 (or Fig. 16) to Circuits A or B (as appropriate) are listed in Table 1. The increase in the fitted value of $C_{\phi}$ at $E=$ $0.72 \mathrm{~V}$ relative to lower potentials, despite the fact that the phase angle $v s . \log$ frequency plots of Fig. 15 indicate that the adsorption pseudo-capacitance is becoming less significant at this potential, is probably a fitting artefact arising from the poor temporal separation of the $R_{\mathrm{p}} C_{\mathrm{dl}}$ and $R_{\mathrm{S}} C_{\phi}$ time contants in this spectrum (i.e. that recorded at $E=0.72 \mathrm{~V}$ ), a phenomenon that was discussed by Macdonald et al. ${ }^{49}$

We postulated above, on the basis of the voltammetric profile of Fig. 12, that the oxide surface of the aged $\mathrm{Fe}$ electrode is disorganised and dispersed in character. This view is confirmed by the low values of the double layer CPE $\alpha$ parameter reported in Table $1(0.67 \leq \alpha \leq 0.81$ over the range of potential investigated). While it is not surprising that the surface roughness associated with an oxide film should lead to a deviation from unity in the value of $\alpha$, the magnitude of this deviation is particularly large in the present case by comparison with other OER anodes that we have investigated. For example in the case of a passive oxide covered $\mathrm{Ni}$ electrode in $1.0 \mathrm{M} \mathrm{NaOH}$ solution, ${ }^{26}$ values of $0.845 \leq \alpha \leq 0.867$ were obtained for the double layer CPE across the potential range associated with significant oxygen evolution current density. Although the physical significance of the $\alpha$ parameter is dubious ${ }^{48}$ it is probably qualitatively reasonable to conclude that, the smaller the value of $\alpha$, the less uniform the electrode surface. With increasing surface roughness and dispersion, the magnitude of $\alpha$ will decrease as the classical concept of the double layer capacitance of an ideally smooth uniform electrode/solution interface becomes progressively less applicable.

Tafel slopes are normally measured directly using DC steady state polarisation methods, however they can also be determined using EIS. The latter method involves the experimental determination of the total Faradaic resistance, $R_{\mathrm{far}}$, where in the present case, $R_{\mathrm{far}}=R_{\mathrm{s}}+R_{\mathrm{p}}$. At an oxygen evolution overpotential $\eta, \dagger$ where simple Tafel behaviour prevails, the current density $i$ is related to $\eta$ via the following expression,

$$
i=i_{0} \exp (2.303 \eta / b)
$$

where $i_{0}$ is the exchange current density for the OER. Taking the derivative of $i$ with respect to $\eta$ :

$$
\frac{\mathrm{d} i}{\mathrm{~d} \eta}=\frac{2.303 i_{0}}{b} \exp (2.303 \eta / b)
$$

We note that $\mathrm{d} i / \mathrm{d} \eta=\mathrm{d} i / \mathrm{d} E=1 / R_{\mathrm{far}}$, and by performing a logarithmic analysis of eqn (8), the following expression is achieved,

$$
\log \left(\frac{1}{R_{\text {far }}}\right)=\frac{E}{b}+\log \left(\frac{2.303 i_{0}}{b}\right)
$$

implying that the inverse slope of a plot of $\log \left(1 / R_{\mathrm{far}}\right)$ against $E$ is equal to the Tafel slope $b$.

$\dagger$ At an applied potential $E$, the overpotential $\eta$ for a given electrochemical process is the difference between $E$ and the standard potential for the process, $E^{0}$, i.e. $\eta=E-E^{0}$. For the oxygen electrode in alkaline solution ( $\mathrm{pH} \mathrm{14}$ ) at $25{ }^{\circ} \mathrm{C}, \mathrm{O}_{2}+2 \mathrm{H}_{2} \mathrm{O}+4 \mathrm{e}^{-} \leftrightarrows 4 \mathrm{OH}^{-}$, $E^{0}=0.401 \mathrm{~V}(v s . \mathrm{NHE})=0.303 \mathrm{~V}(v s . \mathrm{Hg} / \mathrm{HgO}, 1 \mathrm{M})$, ref. 50 
A plot of $\log \left(1 / R_{\mathrm{far}}\right)$ against $E$ based on the listed fitting parameters of Table 1 is presented in Fig. 18. It is apparent that there is satisfactory agreement between the values of the Tafel slopes obtained from the impedance data and those obtained by the steady state polarisation method (see Fig. 13), for the aged Fe electrode in $1.0 \mathrm{M} \mathrm{NaOH}$.

\section{The active site for the OER at oxidised Fe electrodes?}

It has been proposed by Tseung and co-workers ${ }^{51,52}$ that oxygen evolution can only occur on a metal oxide surface, at or above the potential of a given lower oxide/higher oxide redox transition. This hypothesis is consistent with our experience of the OER at passive oxide covered $\mathrm{Ni}^{26}$ and $\mathrm{Co}^{27}$ electrodes in aqueous alkaline solution. When characterising these electrodes voltammetrically, it was observed that the rising edge of the OER current density appeared directly anodic to the $\mathrm{Ni}(\mathrm{II}) \rightarrow \mathrm{Ni}(\mathrm{III})$ oxidation peak in the case of $\mathrm{Ni}$ anodes, and, for Co electrodes, developed from the anodic feature associated with the surface oxidation of $\mathrm{Co}(\mathrm{III}) \rightarrow \mathrm{Co}(\mathrm{IV})$ species.

This raises the question as to which redox transition is associated with the onset of oxygen evolution in the case of oxidised Fe electrodes in alkaline solution. Referring to the voltammograms of Fig. 1 and 2, it would appear that the anodic redox transition, closet in potential to oxygen evolution, is that related to the broad shoulder extending from $\sim-0.5$ to $0.1 \mathrm{~V}-$ a full $750 \mathrm{mV}$ (approximately) below the appearance of the rising edge of the oxygen evolution current. As discussed previously, this voltammetric feature is related to the oxidation of $\mathrm{Fe}$ (II) species to $\mathrm{Fe}(\mathrm{III})$ species. At potentials between the upper limit of this anodic feature and the appearance of the oxygen evolution current, the $\mathrm{Fe}$ voltammogram is characterised by an apparently featureless region of constant background current density. In view of these observations one must ask whether the OER at iron oxide surfaces is somehow different from that occurring at nickel, cobalt and other oxide surfaces, or if indeed the associations between oxygen evolution and redox transitions are merely coincidental? We believe that several somewhat random, if potentially useful observations, made in the course of the present study, can provide some insight into this matter.

The voltammograms of Fig. 19 were recorded after polishing, for one particular iron electrode specimen, on three

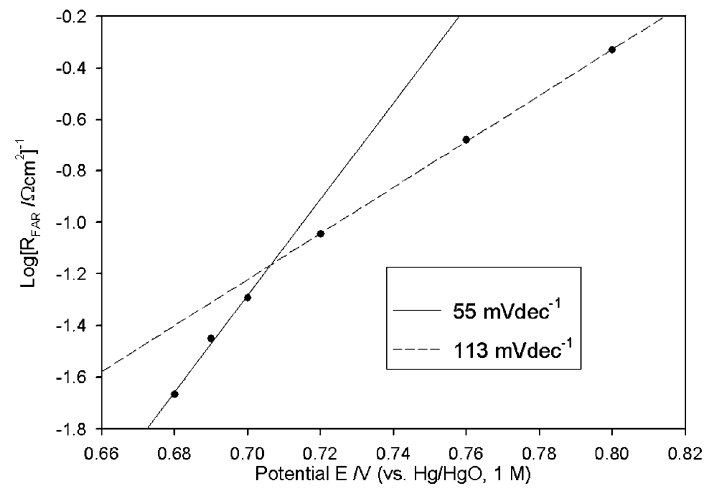

Fig. $18 \log \left(R_{\mathrm{far}}\right)^{-1} v$ s. $\eta$ plots constructed from the impedance data of Fig. 15. 


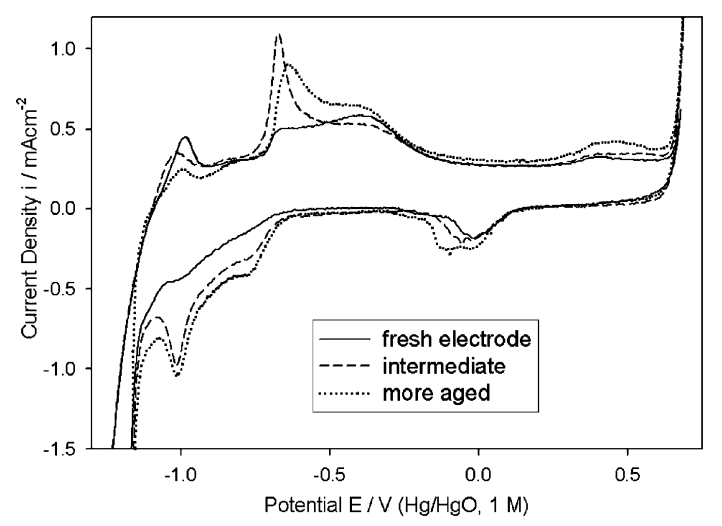

Fig. $19 \mathrm{CV}$ s recorded on different occasions during the experimental service life of a particular polycrystalline iron electrode specimen. The electrode was polished to a "mirror bright" finish in each case - the CVs were recorded in $1.0 \mathrm{M} \mathrm{NaOH}$ at $25^{\circ} \mathrm{C}$, with a scan rate of $40 \mathrm{mV} \mathrm{s}^{-1}$.

different occasions during its experimental service life. The striking feature of these CVs is the additional pair of voltammetric peaks - an anodic peak located at potentials between ca. 0.3 and $0.6 \mathrm{~V}$, and a complementary cathodic peak between approximately 0.1 and $-0.15 \mathrm{~V}$. It is evident from the "more aged" profile, that the magnitude of both "extra" peaks have increased with electrode ageing. It is also especially apparent in the case of this scan, that the rising current associated with oxygen evolution becomes significant at potentials just above the aforementioned anodic peak.

The observation of a pair of redox peaks at potentials similar to those associated with the unidentified features of Fig. 19, is not entirely unprecedented. Joiret et $a l^{23}$ have reported similar features in a voltammogram performed on an iron film electrodeposited on a gold EQCM electrode. By referencing the Pourbaix diagram for iron ${ }^{53}$ they have attributed their observed peak pair to a $\mathrm{Fe}^{3+} / \mathrm{Fe}^{6+}$ redox transition. Furthermore a potential modulated reflectance (PMR) spectroscopy study ${ }^{20}$ on an Fe electrode in $1.0 \mathrm{M} \mathrm{NaOH}$, concluded that $\alpha-\mathrm{Fe}_{2} \mathrm{O}_{3}$ was oxidised to $\mathrm{FeO}_{4}{ }^{2-}$ as the potential of significant oxygen evolution was approached.

In view of the thermodynamic considerations and experimental results cited above, we propose a tentative designation of the unidentified peak pair of Fig. 19 to a $\mathrm{Fe}^{3+} / \mathrm{Fe}^{6+}$ redox transition. Therefore the "missing" lower oxide/higher oxide transition for iron oxide might well be the surface oxidation of $\mathrm{Fe}(\mathrm{III})$ to $\mathrm{Fe}(\mathrm{VI})$ species. To act as catalytic centres for the OER, these $\mathrm{Fe}(\mathrm{vI})$ entities must be somehow stabilised on the oxide surface and are therefore likely to be somewhat different in formal composition to the soluble $\mathrm{FeO}_{4}{ }^{2-}$ species. We discuss elsewhere ${ }^{45}$ how such stabilisation might occur.

Of course the question arises as to why the peaks attributed here to a $\mathrm{Fe}^{3+} / \mathrm{Fe}^{6+}$ redox transition, are not always observed in voltammograms characterising oxidised $\mathrm{Fe}$ electrode surfaces. The reason for this is presently unclear. The electrode for which the CVs of Fig. 19 were recorded, was prepared (apparently) in the same manner, and from the same iron foil as the other Fe electrodes utilised. It can only be speculated, that some aspect of the electrode preparation, has caused the activation of the surface with respect to the $\mathrm{Fe}(\mathrm{III}) \rightarrow \mathrm{Fe}(\mathrm{VI})$ oxidation process. In the more general case, voltammetric peaks for the $\mathrm{Fe}(\mathrm{III}) \leftrightarrow \mathrm{Fe}(\mathrm{VI})$ redox transition are not observed, possibly because an appreciable surface concentration of the catalytic $\mathrm{Fe}(\mathrm{vI})$ entity arises only at the potential corresponding to the appearance of a substantial oxygen evolution current. We have previously discussed ${ }^{54}$ how the oxidative formation of the active material for the OER at thermally prepared $\mathrm{RuO}_{2}$ (and other) anodes may also not be sensitive to characterisation as an anodic peak in a voltammetry experiment. The discussion of this paragraph has resonance with a recent article by Bond et al. ${ }^{55}$ on "hidden" surface redox transitions. For DC voltammetric responses dominated by irreversible catalytic processes involving solution phase species, these workers have shown that large amplitude Fourier transformed AC voltammetry is sensitive, in the higher harmonics, to coupled surface redox transitions of the working electrode material.

\section{Kinetic mechanistic analysis of the OER}

In summary, referring to the kinetic data of Fig. 9-11, 13, 14 and 18 , a kinetic analysis and associated reaction mechanism for the OER at the various oxidised Fe electrodes studied, must predict that $b=2.303 \times R T / F$ and the reaction order $m_{\mathrm{OH}-}=3 / 2$ at low potentials, changing to $b=2.303 \times 2 R T / F$ and $m_{\mathrm{OH}-}=1$ at higher potentials.

In our initial communication ${ }^{11}$ of some years ago, we proposed that oxygen evolution occurs at muticycled iron electrodes in aqueous alkaline media, according to the following modified Krasil'shchikov ${ }^{56}$ scheme:

$$
\begin{aligned}
\mathrm{S}+\mathrm{OH}^{-} & \rightarrow \mathrm{SOH}+\mathrm{e}^{-} \\
\mathrm{SOH}+\mathrm{OH}^{-} & \rightarrow \mathrm{SO}^{-}+\mathrm{H}_{2} \mathrm{O} \\
\mathrm{O}^{-}+\mathrm{OH}^{-} & \rightarrow \mathrm{SO}_{2} \mathrm{H}^{-}+\mathrm{e}^{-} \\
\mathrm{SO}_{2} \mathrm{H}^{-}+\mathrm{OH}^{-} & \rightarrow \mathrm{S}+\mathrm{O}_{2}+\mathrm{H}_{2} \mathrm{O}+2 \mathrm{e}^{-}
\end{aligned}
$$

In this reaction scheme $\mathrm{S}$ represents an electrocatalytically active oxy-iron surface site, which in view of the discussion of the previous section may well be a stabilised Fe(vi) entity. Our previous analysis ${ }^{11}$ assumed Langmuir adsorption conditions, and with the application of the steady state approximation to obtain an expression for $a_{\mathrm{SOH}}$, the steady state activity of the surface bonded species formed in step (A I), one obtains after some algebra that the current density/ overpotential response takes the form:

$$
i=\frac{n F k_{\mathrm{I}}^{\prime 0} k_{\mathrm{II}} a_{\mathrm{S}} a_{\mathrm{OH}}^{2} \exp \left[\frac{\beta F \eta}{R T}\right]}{k_{-\mathrm{I}}^{\prime 0} \exp \left[-\frac{(1-\beta) F \eta}{R T}\right]+k_{\mathrm{II}} a_{\mathrm{OH}}}
$$

In eqn (10), $k_{\text {I }}^{\prime 0}$ and $k_{-I}^{\prime 0}$ are standard electrochemical rate constants for the electrochemical step (A I) in the forward and reverse directions respectively, $k_{\mathrm{II}}$ is the rate constant for the chemical step (A II), $a_{\mathrm{S}}$ represents the surface activity of the active site $\mathrm{S}, a_{\mathrm{OH}}$ is the $\mathrm{OH}^{-}$activity of the electrolyte solution, while $\beta$ is the symmetry factor associated with the electron transfer energy barrier. When ${k^{\prime}}_{-\mathrm{I}} \gg k_{\mathrm{II}} a_{\mathrm{OH}}$, which 
corresponds to (A II) being the rate determining step (RDS), eqn (10) reduces to:

$$
i=n F k_{\mathrm{II}} a_{\mathrm{S}} a_{\mathrm{OH}}^{2}\left\{\frac{k_{\mathrm{I}}^{\prime 0}}{k_{-\mathrm{I}}^{\prime 0}}\right\} \exp \left[\frac{F \eta}{R T}\right]
$$

On the other hand when $k_{-\mathrm{I}}^{\prime 0} \ll k_{\mathrm{II}} a_{\mathrm{OH}}$, eqn (10) becomes:

$$
i=n F k_{\mathrm{I}}^{\prime 0} a_{\mathrm{S}} a_{\mathrm{OH}} \exp \left[\frac{\beta F \eta}{R T}\right]
$$

This expression will be valid when the initial discharge step (A I) is rate limiting. A logarithmic analysis of eqn (11) yields a Tafel slope of $b=\mathrm{d} E / \mathrm{d} \log i=\mathrm{d} \eta / \mathrm{d} \log i=2.303 \times R T / F$. Correspondingly, from eqn (12), assuming a symmetrical electron transfer energy barrier for step (A I) (i.e. $\beta=1 / 2$ ), a similar analysis yields $b=2.303 \times 2 R T / F$. However, while the formal kinetic analysis of pathway (A) can satisfactorily account for the experimentally observed Tafel slope parameters, by admitting a change in the RDS from step (A II) to step (A I) with increasing applied potential, the predictions with respect to the reaction order are not totally in accord with the measured data. From eqn (11) we note that $m_{\mathrm{OH}-}=$ $\left(\partial \log i / \partial \log a_{\mathrm{OH}}\right)_{\eta}=2$, instead of a value of $3 / 2$ as experimentally observed. The correct reaction order of unity is predicted from eqn (12) for higher overpotentials. Hence our original pathway propostion ${ }^{11}$ (which was published without the benefit of experimental reaction order data) must be modified.

A plausible alternative mechanism is as follows. The first two steps in the process are given by,

$$
\begin{aligned}
\mathrm{S}+\mathrm{OH}^{-} & \rightarrow \mathrm{S}-\mathrm{OH}+\mathrm{e}^{-} \\
\mathrm{S}-\mathrm{OH}+\mathrm{OH}^{-} & \rightarrow \mathrm{S}-\mathrm{H}_{2} \mathrm{O}_{2}+\mathrm{e}^{-}
\end{aligned}
$$

where $\mathrm{S}-\mathrm{H}_{2} \mathrm{O}_{2}$ represents physisorbed hydrogen peroxide. The physisorbed intermediate is then catalytically decomposed according to the following sequence of reactions:

$$
\begin{aligned}
\mathrm{S}-\mathrm{H}_{2} \mathrm{O}_{2}+\mathrm{OH}^{-} & \rightarrow \mathrm{S}-\mathrm{HO}_{2}^{-}+\mathrm{H}_{2} \mathrm{O} \\
\mathrm{S}-\mathrm{H}_{2} \mathrm{O}_{2}+\mathrm{S}-\mathrm{HO}_{2}{ }^{-} & \rightarrow \mathrm{O}_{2}+\mathrm{H}_{2} \mathrm{O}+\mathrm{OH}^{-}
\end{aligned}
$$

This type of pathway was first devised by Bockris and Otagawa $^{57}$ for perovskite anodes in alkaline solution. We now proceed with a kinetic analysis of this mechanism and assume that at lower overpotentials there prevails an intermediate coverage of $\mathrm{S}-\mathrm{OH}$ species. Therefore a Temkin adsorption isotherm is applicable. ${ }^{58-61}$ This approach differs from our previous analysis ${ }^{11}$ where a Langmuir adsorption isotherm was assumed. We adopt a similar approach to the application of the Temkin isotherm, as that taken by Damjanovic et al. $^{62}$ in an important early work on OER kinetics. These workers based their analysis of coverage effects due to adsorbed intermediates, on the principle that a decrease in the free energy of adsorption of an intermediate species (with increasing total coverage) that is a product of a given step, results in an increase in the free energy of activation for that step. In contrast, a decrease in the free energy of adsorption of an intermediate species, which is a reactant in a particular step, will cause a decrease in the free energy of activation for the step. In terms of this model the free energy of adsorption of a given species $i$, depends to the total fractional coverage $\theta^{59,62}$ of all adsorbed reaction intermediate species on the electrode surface according to,

$$
\Delta G^{\prime 0}=\Delta G^{\prime 0}{ }_{\theta}-r_{i} \theta
$$

since it is the sites remaining beyond the overall fractional coverage that determine, through the respective $r$ values, the energy of adsorption that $i$ will experience when adsorbed. The term $r_{i}$ in eqn (13) is clearly the rate of change of the free energy of adsorption of species $i$ with the total coverage.

Let us now consider the first electron transfer step in the modified reaction sequence. The forward reaction flux $j_{I}$ (units: $\mathrm{mol} \mathrm{cm}^{-2} \mathrm{~s}^{-1}$ ) is given by:

$$
j_{\mathrm{I}}=k_{\mathrm{I}}^{\prime 0} a_{\mathrm{OH}}\left(1-\theta_{\mathrm{SOH}}\right) \exp \left[\frac{\beta \eta F}{R T}\right] \exp \left[\frac{-\gamma r_{\mathrm{SOH}} \theta}{R T}\right]
$$

In this expression $\theta_{\mathrm{SOH}}$ denotes the fractional of the electrosorbed S-OH species formed in step (B I), while $\gamma$ is a symmetry factor, with $0<\gamma<1$ and $\gamma=1-\beta$. The reverse desorption step is described by the following expression:

$$
j_{-\mathrm{I}}=k_{-\mathrm{I}}^{\prime 0} \theta_{\mathrm{SOH}} \exp \left[\frac{-(1-\beta) \eta F}{R T}\right] \exp \left[\frac{(1-\gamma) r_{\mathrm{SOH}} \theta}{R T}\right]
$$

We assume that at low overpotentials, step (B I) is rate determining and that the first step is at pseudo-equilibrium. Since an intermediate total fractional coverage is assumed $(0.2 \leq \theta \leq 0.8)$, it is possible, under these conditions, that a significant fractional coverage, $\theta_{\mathrm{II}}$, of the intermediate formed in the RDS $\left(\mathrm{S}-\mathrm{H}_{2} \mathrm{O}_{2}\right)$ may be achieved. Consequently the net reaction flux must be written as:

$$
\begin{aligned}
j & =j_{\mathrm{II}} \\
& =k_{\mathrm{II}}^{\prime 0} a_{\mathrm{OH}} \theta_{\mathrm{SOH}} \exp \left[\frac{\beta \eta F}{R T}\right] \exp \left[\frac{(1-\gamma) r_{\mathrm{SOH}} \theta-\gamma r_{\mathrm{II}} \theta}{R T}\right]
\end{aligned}
$$

The free energy of adsorption for the physisorbed hydrogen peroxide entity formed in the second step is likely to be much less sensitive to the value of the total fractional coverage $\theta$, than is the case for the chemisorbed $\mathrm{S}-\mathrm{OH}$ species formed in the initial step, and so it is appropriate to assume that $r_{\mathrm{SOH}} \gg r_{\mathrm{II}}$. In this case eqn (16) reduces to:

$$
j=k_{\mathrm{II}}^{\prime 0} a_{\mathrm{OH}} \theta_{\mathrm{SOH}} \exp \left[\frac{\beta \eta F}{R T}\right] \exp \left[\frac{(1-\gamma) r_{\mathrm{SOH}} \theta}{R T}\right]
$$

In order to proceed further we invoke the quasi-equilibrium hypothesis to obtain an expression for $\theta$. When quasi-equilibrium prevails we have $j_{I}=j_{-I}$, and so from eqn (14) and (15) we obtain:

$$
\begin{aligned}
\left\{\frac{\theta_{\mathrm{SOH}}}{1-\theta_{\mathrm{SOH}}}\right\} \exp \left[\frac{r_{\mathrm{SOH}} \theta}{R T}\right] & =\frac{k_{\mathrm{II}}^{\prime 0}}{k_{-\mathrm{I}}^{\prime 0}} a_{\mathrm{OH}} \exp \left[\frac{F \eta}{R T}\right] \\
& =K a_{\mathrm{OH}} \exp \left[\frac{F \eta}{R T}\right]
\end{aligned}
$$


For intermediate values of $\theta_{\mathrm{SOH}}$ the linear pre-exponential term in $\theta_{\mathrm{SOH}}$ can be assumed to approach unity, ${ }^{59-61}$ thus yielding the following simplification of eqn (18):

$$
\begin{aligned}
\exp \left[\frac{r_{\mathrm{SOH}} \theta}{R T}\right] & =K a_{\mathrm{OH}} \exp \left[\frac{F \eta}{R T}\right] \\
r_{\mathrm{SOH}} \theta & =R T \ln \left(K a_{\mathrm{OH}}\right)+F \eta
\end{aligned}
$$

We now substitute this expression for $r_{\mathrm{SOH}} \theta$ into eqn (17) and after some algebra obtain:

$$
j=k_{\mathrm{II}}^{\prime 0} a_{\mathrm{OH}}^{2-\gamma} \theta_{\mathrm{SOH}} K^{1-\gamma} \exp \left[\frac{(1-\gamma+\beta) \eta F}{R T}\right]
$$

Taking natural logarithms we obtain:

$$
\ln j=\ln \left(k_{\mathrm{II}}^{\prime 0} \theta_{\mathrm{SOH}} K^{1-\gamma}\right)+\ln \left(a_{\mathrm{OH}}^{2-\gamma}\right)+\frac{(1-\gamma+\beta) F \eta}{R T}
$$

Setting $\gamma=\beta=1 / 2$ achieves:

$$
\begin{gathered}
b=\left(\frac{\partial \eta}{\partial \log j}\right)_{a_{\mathrm{OH}}}=2.303 \frac{R T}{(1-\gamma+\beta) F}=2.303 \frac{R T}{F} \\
m_{\mathrm{OH}^{-}}=\left(\frac{\partial \ln j}{\partial \ln a_{\mathrm{OH}}}\right)_{\eta}=2-\gamma=\frac{3}{2}
\end{gathered}
$$

Hence, the experimental mechanistic parameters observed at low overpotentials are rationalised.

Furthermore, the high potential behaviour may be explained as follows. The experimentally observed $b=\sim 2.303 \times 2 R T / F$ Tafel slope may be ascribed to a change in the surface coverage of adsorbed intermediates at higher potentials to a situation where $\theta_{\mathrm{SOH}} \approx \theta \rightarrow 1$ (i.e. Langmuir isotherm as the total fractional coverage tends to unity). Where Langmuir adsorption conditions prevail, the $r_{i}$ term in eqn (13) tends to zero and eqn (17) thus reduces to:

$$
j=k_{\mathrm{II}}^{\prime 0} a_{\mathrm{OH}} \exp \left[\frac{\beta \eta F}{R T}\right]
$$

Performing a similar logarithmic analysis to that of eqn (21-23) (again assuming $\beta=1 / 2$ ), it can readily be shown that the predicted values for the Tafel slope and reaction order are $b=2.303 \times 2 R T / F$ and $m_{\mathrm{OH}-}=1$, respectively.

The important point to note here is that the dual Tafel slope behaviour is not due to a change in rate determining step, but is due solely to the potential dependence of the total fractional coverage $\theta$ of the electrosorbed reaction intermediates.

At this point, we emphasise the central importance and significance of the fact that the hydrogen peroxide entity formed in step (B II) is envisaged to be physisorbed as opposed to chemisorbed. This is not merely a contrivance to accommodate for the adsorption of intact hydrogen peroxide molecules at the oxide surface. What follows was implicit in the analysis of Bockris and Otagawa ${ }^{57}$ when they first outlined this type of OER pathway, however we feel that it is worth stating explicitly.
Below, we outline the so-called Bockris electrochemical OER pathway: ${ }^{57}$

$$
\begin{aligned}
\mathrm{S}+\mathrm{OH}^{-} & \rightarrow \mathrm{SOH}+\mathrm{e}^{-} \\
\mathrm{SOH}+\mathrm{OH}^{-} & \rightarrow \mathrm{SO}+\mathrm{H}_{2} \mathrm{O}+\mathrm{e}^{-} \\
2 \mathrm{SO} & \rightarrow 2 \mathrm{~S}+\mathrm{O}_{2}
\end{aligned}
$$

At first glance it would appear, that the formal kinetic analysis of a pathway such as this, with step (C II) as RDS, should to be identical to the analysis for scheme (B), in that they both consist of an electrochemical rate limiting second step, in which an $\mathrm{OH}^{-}$ion is adsorbed from solution. It is true that this is the case under Langmuir adsorption conditions, i.e. $\theta_{\mathrm{SOH}} \approx \theta \rightarrow 1$ or 0 . Indeed, where the Temkin isotherm applies, the rate equations for step (C I) in the forward and reverse directions are identical to eqn (14) and (15), respectively, while the general rate equation for the rate determining (C II) step takes the same form as eqn (16). However the simplification that previously took us from eqn (16) to (17) is not permissible for pathway $\mathrm{C}$. In the case of the chemisorbed $\mathrm{O}$ atom formed in step (C II), the Temkin parameter $r_{\mathrm{II}}$ is likely to be similar in magnitude to $r_{\mathrm{SOH}}$, since both the $\mathrm{SOH}$ and SO intermediate species involve chemical bonding by oxygen atoms to the substrate S. Setting $r_{\mathrm{SO}}=r_{\mathrm{SOH}}=r$, substituting into eqn (16) and as before setting $\gamma=1 / 2$ yields:

$$
j=k_{\mathrm{II}}^{\prime 0} a_{\mathrm{OH}} \theta_{\mathrm{SOH}} \exp \left[\frac{\beta \eta F}{R T}\right]
$$

This expression differs from eqn (24), for the flux of the overall reaction with step (B II) rate determining under high coverage Langmuir conditions (at higher $\eta$ ), only by the pre-exponential factor of $\theta_{\mathrm{SOH}}$. It is therefore trivial to show that a kinetic analysis of pathway $\mathrm{C}$ with the second step as the RDS under Temkin adsorption conditions, predicts the same values of $b=2.303 \times 2 R T / F$, and $m_{\mathrm{OH}-}=1$, that prevail under the Langmuir isotherm with $\theta \rightarrow 1$. This implies that, regardless of the magnitude of the total fractional coverage of intermediates (i.e. whether the Langmuir or Temkin adsorption isotherm is admitted), pathway $\mathrm{C}$ cannot rationalise the observed, lower overpotential, experimental kinetic data of $b \approx 2.303 \times R T / F$, with $m_{\mathrm{OH}-} \approx 3 / 2$, despite its apparent similarity to pathway B. Essentially then, the envisaged formation of the physisorbed hydrogen peroxide entity in the rate determining step (B II), represents a physically reasonable situation where $r_{\mathrm{II}} \ll r_{\mathrm{SOH}}$. If an alternative physical scenario were devised where this condition is also suggested, then that proposal would be worthy of consideration in the rationalisation of the experimental data. It must however be said, that the admission of the physisorbed hydrogen peroxide concept provides a satisfying solution to the problem, both from the point of view of the mathematical analysis, and the requirment for real physical viability.

Indeed, amongst the various OER pathways that we have encountered in the literature, the physisorbed peroxide pathway is uniquely capable of accounting for the experimental kinetic parameters that we have observed for both the lower and upper Tafel regions. 


\section{Conclusions}

The $\mathrm{Fe}(\mathrm{II}) / \mathrm{Fe}(\mathrm{III})$ redox switching reaction of multicycled polymeric iron oxyhydroxide films in aqueous alkaline solution has been has been described (eqn (1)) in terms of a two electron per "dimeric unit" electron transfer reaction. The structural similarity between the outer dispersed hydrous oxide formed on Fe electrodes and other electroactive polymer films is indicated by the similar magnitude of the average charge transport diffusion coefficient $D_{\mathrm{CT}}$ (calculated in the present work) for the former and literature values of this parameter for electrodes modified by polymers such as polyaniline or poly(pyrrole).

A reasonable mechanism has been proposed for oxygen evolution in basic solutions, applicable to both muticycled and aged bright polycrystalline iron electrodes, which is good accord with experimental observation. Voltammetric evidence has been presented, which provides tentative support for our earlier hypothesis that oxygen evolution occurs at $\mathrm{Fe}(\mathrm{VI})$ based active sites on the surface of oxidised iron anodes in alkaline media.

\section{References}

1 L. D. Burke and M. E. G. Lyons, in Modern Aspects of Electrochemistry, ed. R. E. White, J. O'M. Bockris and B. E. Conway, Plenum Press, New York, 1986, vol. 18, p. 169.

2 L. D. Burke and E. J. M. O'Sullivan, J. Electroanal. Chem., 1981, 117, 155.

3 L. D. Burke, M. I. Casey, V. J. Cunnane, O. J. Murphy and T. A. M. Twomey, J. Electroanal. Chem., 1985, 189, 353.

4 L. D. Burke, in Electrodes of Conductive Metallic Oxides, Part A, ed. S. Trasatti, Elsevier, Amsterdam, 1980, pp. 141-181.

5 L. D. Burke, M. E. G. Lyons and D. P. Whelan, J. Electroanal. Chem., 1982, 139, 131.

6 L. D. Burke, M. E. G. Lyons, E. J. M. O'Sullivan and D. P. Whelan, J. Electroanal. Chem., 1981, 122, 403.

7 L. D. Burke and M. B. C. Roche, J. Electroanal. Chem., 1984, 164, 315.

8 L. D. Burke and T. A. M. Twomey, J. Power Sources, 1984, 12, 203.

9 L. D. Burke and M. J. G. Ahern, J. Electroanal. Chem., 1985, 183, 183.

10 L. D. Burke and D. P. Whelan, J. Electroanal. Chem., 1984, 162, 121.

11 M. E. G. Lyons and L. D. Burke, J. Electroanal. Chem., 1984, 170, 377.

12 L. D. Burke and M. E. G. Lyons, J. Electroanal. Chem., 1986, 198, 347.

13 D. E. Hall, J. Electrochem. Soc., 1983, 130, 317.

14 L. Ojefors, J. Electrochem. Soc., 1976, 123, 1691.

15 D. D. MacDonald and D. Owen, J. Electrochem. Soc., 1973, 120, 317.

16 H. Neugebauer, G. Nauer, N. Brinda-Konopik and G. Gidaly, J. Electroanal. Chem., 1981, 122, 381.

17 F. Beck, R. Kaus and M. Oberst, Electrochim. Acta, 1985, 30, 173.

18 R. S. S. Guzman, J. R. Vilche and A. J. Arvia, Electrochim. Acta, 1979, 24, 395.

19 S. Juanto, R. S. S. Guzman, J. O. Zerbino, J. R. Vilche and A. J. Arvia, Electrochim. Acta, 1991, 36, 1143.

20 G. Larramona and C. Gutierrez, J. Electrochem. Soc., 1989, 136, 2171.

21 R. Simpraga and B. E. Conway, J. Electroanal. Chem., 1991, 313, 161.

22 S. T. Amaral, E. M. A. Martini and I. L. Muller, Corros. Sci., $2001,43,853$.

23 S. Joiret, M. Keddam, X. R. Novoa, M. C. Perez, C. Rangel and H. Takenouti, Cem. Concr. Compos., 2002, 24, 7.

24 M. E. G. Lyons, Ann. Rep. C. R. Soc. Chem., 1991, 88, 135.

25 B. E. Conway and H. Angerstein-Kozlowska, Acc. Chem. Res., 1981, 14, 49.

26 M. E. G. Lyons and M. P. Brandon, Int. J. Electrochem. Sci., 2008, 3, 1386 .
27 M. E. G. Lyons and M. P. Brandon, Int. J. Electrochem. Sci., 2008, 3, 1425.

28 J. C. Jernigan, C. E. D. Chidsey and R. W. Murray, J. Am. Chem. Soc., 1985, 107, 2824.

29 C. E. D. Chidsey and R. W. Murray, J. Phys. Chem., 1986, 90, 1479 .

30 E. F. Dalton, N. A. Surridge, J. C. Jernigan, K. O. Wilbourn, J. S. Facci and R. W. Murray, Chem. Phys., 1990, 141, 143.

31 J. C. Jernigan, N. A. Surridge, M. E. Zvanut, M. Silver and R. W. Murray, J. Phys. Chem., 1989, 93, 4620.

32 S. Ardizzone, G. Fregonara and S. Trasatti, Electrochim. Acta, 1990, 35, 263.

33 K. Aoki, K. Tokuda and H. Matsuda, J. Electroanal. Chem., 1983, 146, 417.

34 CRC Handbook of Chemistry and Physics, ed. D. R. Linde, CRC Press, 88th edn, 2007, pp. 4-68.

35 Encyclopedia of Minerals, ed. W. L. Roberts, T. J. Campbell and G. R. Rapp, Jr, Van Nostrand Reinhold, New York, 2nd edn, 1990, p. 273.

36 I. Rubenstein, E. Sabatani and J. Rishpon, J. Electrochem. Soc., 1987, 134, 3078.

37 J. C. Lacroix, K. K. Kanazawa and A. Diaz, J. Electrochem. Soc., 1989, 136, 1308.

38 M. E. G. Lyons, H. G. Fay, T. McCabe, J. Corish, J. G. Vos and A. J. Kelly, J. Chem. Soc., Faraday Trans., 1990, 86, 2905.

39 R. M. Penner and C. R. Martin, J. Phys. Chem., 1989, 93, 984.

40 P. Burgmayer and R. W. Murray, J. Am. Chem. Soc., 1982, 104, 6139

41 K. Kinoshita, Electrochemical Oxygen Technology, Wiley-Interscience, New York, 1992, ch. 2, pp. 78-99.

42 J. O'M. Bockris and S. U. M. Khan, Surface Electrochemistry-A Molecular Level Approach, Plenum Press, New York, 1993, pp. 296-297, 319-349.

43 M. Gattrell and B. MacDougall, in Handbook of Fuel Cells, Fundamentals Technology and Applications, Vol. 2, Electrocatalysis, eds. W. Vielstich, A. Lamm and H. A. Gasteiger, John Wiley and Sons, Chichester, 2003, pp. 443-464.

44 R. A. Robinson and R. H. Stokes, Electrolyte Solutions, Butterworth \& Co. Ltd, London, Revised 2nd edn, 1965, p. 492.

45 M. E. G. Lyons and M. P. Brandon, Int. J. Electrochem. Sci., 2008, 3, 1463.

46 M. E. G. Lyons and M. P. Brandon, J. Electroanal. Chem., 2009, in press.

47 D. A. Harrington and B. E. Conway, Electrochim. Acta., 1987, 32, 1703.

48 B. E. Conway, in Impedance Spectroscopy-Theory, Experiment, and Applications, eds. E. Barsoukov and J. R. Macdonald, J. Wiley \& Sons, 2nd edn, 2005, pp. 469-497.

49 J. R. Macdonald, J. Schoonman and A. P. Lehnen, J. Electroanal. Chem., 1982, 131, 77.

50 A. Lasia, in Handbook of Fuel Cells, Fundamentals Technology and Applications, Vol. 2, Electrocatalysis, ed. W. Vielstich, A. Lamm and H. A. Gasteiger, John Wiley and Sons, Chichester, 2003, pp. 416-440.

51 A. C. C. Tseung and S. Jasem, Electrochim. Acta., 1977, 22, 31.

52 P. Rasiyah and A. C. C. Tseung, J. Electrochem. Soc., 1984, 131, 803.

53 M. Pourbaix, Atlas of Electrochemical Equilibrium in Aqueous Solutions, Pergamon Press, London, 1965, pp. 307-321.

54 M. E. G. Lyons and L. D. Burke, J. Chem. Soc., Faraday Trans. 1, 1987, 83, 299.

55 B. Lertanantawong, A. P. O'Mullane, W. Surareungchai, M. Somasundrum, L. D. Burke and A. M. Bond, Langmuir, 2008, 24, 2856.

56 A. I. Krasil'shchikov, Zh. Fiz. Khim., 1963, 37, 531.

57 J. O'M. Bockris and T. Otagawa, J. Phys. Chem., 1983, 87, 2960.

58 M. I. Temkin, Zh. Fiz. Khim., 1941, 15, 296.

59 B. E. Conway and E. Gileadi, Trans. Faraday Soc., 1962, 58, 2493.

60 B. E. Conway and E. Gileadi, in Modern Aspects of Electrochemistry, ed. J. O'M. Bockris and B. E. Conway, Butterworths, London, 1964, vol. 3, p. 347.

61 M. E. G. Lyons, W. Breen and J. F. Cassidy, J. Chem. Soc., Faraday Trans., 1991, 87, 115.

62 A. Damjanovic, A. Dey and J. O'M. Bockris, Electrochim. Acta., 1966, 11, 791 